Ann. Biol. anim. Bioch. Biophys., I966, 6 (4), 553-585.

REVUE BIBLIOGRAPHIQUE

\title{
BIOLOGIE DE LA REPRODUCTION DU MALE ET DES SPERMATOZOÏDES CHEZ DROSOPHILA MELANOGASTER
}

\author{
C. PERRIN-WALDEMER \\ Laboratoire de Zoologie et Biologie cellulaire, \\ Faculté des Sciences, 63 - Clermont-Ferrand \\ 1, Avenue Vercingétorix
}

\section{SOMMAIRE}

\section{PREMIÈRE PARTIE}

\section{LES SPERMATOZOÏDES CHEZ LE MALE}

Chapitre premier. - Production des Spermatozoïdes.

I. Bref rappel de la gamétogenèse et terminologie de la spermiogenèse

2. Détermination de la durée de la gamétogenèse

3. Rythme de la gamétogenèse (cinétique de production des spermatozoïdes)

4. Progression dans les voies génitales mâles

5. Ejaculation

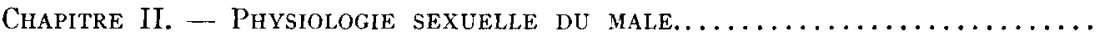

I. Acquisition de la maturité sexuelle

2. Variation de la fécondité au cours du temps

A - Avec nombre de femelles non limité

a) Fréquence des accouplements

b) Nombre de descendants

c) Influence de la densité de population sur l'activité sexuelle du mâle

B - Fréquence d'accouplements en fonction d'un nombre déterminé de femelles

3. Divers types de stérilité

A - Stérilité après copulations multiples

B - Stérilité et sénescence 
C - Stérilité sporadique

D - Stérilité consécutive aux irradiations

4. Stockage et résorption des spermatozoïdes

A - Partisans du stockage

$\mathrm{B}$ - Partisans de la résorption

5. Rôle des glandes accessoires (paragonia) chez le mâle
A - Rôle principal
$\mathrm{B}$ - Conséquences
C - Autres rôles envisagés par les auteurs
D - Nature chimique de la sécrétion

Cirapitre III. - Influence de Divers facteurs.

I. Facteurs génétiques

A - Relation entre durée d'accouplement et génotype

B - Relation entre l'hétérozygotie et la vigueur des mâles

2. Facteurs expérimentaux

A - Action des rayons $\mathrm{X}$

B -- Action de la chaleur

C - Action du froid

\section{DEUXIÈME, PARTIE;}

BIOLOGIE DES SPERMATOZOÏDES DANS LES VOIES GÉNITALES FEMELLES

Chapitre premier. - Nombre de spermatozoïdes reçus et conservés........

r. Nombre de spermatozoïdes transférés par copulation

2. Nombre de spermatozoïdes stockés et modalités de stockage

3. Influence de divers facteurs sur le stockage

A - Influences raciales

B - Viabilité différentielle des spermatozoïdes

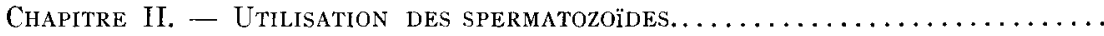

I. Rendement

2. Mécanisme d'utilisation

3. Influence de l'âge de la femelle

4. Polyspermie et monospermie dans l'œuf de Drosophile

5. Problème du mélange des spermatozoïdes au cours des fécondations successives

A - Hypothèse du mélange au hasard

B - Stratification

$\mathrm{C}$ - Déplacement

D - Influence de la vitalité des spermatozoïdes

6. Résorption des spermatozoïdes chez la femelle

A - Influence de la nutrition

$\mathrm{B}$ - Influence du froid 
Chapitre III. - Influence de la fécondation Sur la physiologie sexuelle DE LA FEMELlE......................... 576

A - Comportement sexuel : état de réceptivité ou non

B - Fécondité de la femelle en rapport avec la fertilisation

C - Corpus allatum et fécondation

Conclusions. 578

A - Bilan des connaissances sur les points traités

$\mathrm{B}$ - Perspectives sur d'autres problèmes qui restent à élucider

RÉSUMÉ ANGLAIS

$58 \mathbf{1}$

Bibliographie. 


\section{INTRODUCTION}

Aucune revue d'ensemble des travaux effectués sur le mâle de la Drosophile n'a encore été entreprise. Les publications parues ces cinquante dernières années n'abordent souvent que des points particuliers, et l'accord entre les auteurs est loin d'être toujours réalisé. Par ailleurs on note depuis quinze ans environ, une fréquence accrue des travaux sur la reproduction des Insectes, suscités par l'étude des effets des rayonnements sur les cellules sexuelles. L'étude de la spermatogenèse chez la Drosophile fait désormais partie des travaux classiques (voir CoOper, Bodenstein, in Demerec, 1950). En revanche, la physiologie sexuelle du mâle a subi des apports nouveaux qui n'ont pas été rassemblés depuis l'ouvrage de Demerec, où l'auteur s'en tient encore aux premières observations, néanmoins fondamentales de Nonidez (i920).

C'est pourquoi il nous a paru utile d'effectuer cette mise au point bibliographique afin de faire le bilan des questions physiologiques qui semblent résolues de celles qui ne le sont pas encore.

Nous ne consacrerons qu'un court paragraphe au domaine de la radiobiologie, qui à lui seul, a déjà justifié plusieurs mises au point : celle de Grosch (1962) et plus récemment celle de MaNDL (1964) où une bibliographie importante est consacrée aux Insectes, et au mâle de la Drosophile notamment.

Un autre domaine en évolution rapide concerne celui de la stérilisation des mâles d'Insectes soit par utilisation des rayons $\mathrm{X}$, soit par des agents chimiques (héliotrine, aziridines, etc.). Il sort du cadre de notre étude bien qu'il constitue une application directe de la biologie des spermatozoïdes.

On ne parlera pas des données anatomiques que l'on peut trouver dans l'ouvrage classique de Demerec (1950), ni des données physiologiques générales sur la reproduction, qui sont développées dans les traités de Chiauvin (1956), de Rockstein (1964) et de Wiggleswortir (1965).

Les données biophysiques et biochimiques concernant le sperme de Drosophila sont pratiquement inexistantes, les travaux cytochimiques rares $\left({ }^{1}\right)$, aussi nous aborderons directement l'étude des spermatozoïdes che\% le mâle par celle de leur production, puis nous examinerons les problèmes de la physiologie sexuelle chez ce dernier. Nous envisagerons ensuite la survie et la destinée des gamètes mâles dans les voies génitales femelles jusqu’à la fécondation, ainsi que les répercussions de la fécondation sur la physiologie sexuelle de la femelle.

(1) Citons une étude de DaEms et al. (Ig63) sur la localisation de l'A'TP-ase dans le flagelle du spermatozoìde de $D . m$. 


\title{
PREMIÈRE: PAR'TIE
}

\section{LES SPERMATOZOÏDES CHEZ LE MALE}

\author{
CHAPI'TRE PREMIER \\ PRODUCTION DES SPERMATOZOÏDES
}

\author{
I. Bref rappel de la Gamétogenése \\ et terminologie de la spermiogenèse
}

Les grandes lignes du développement des cellules germinales mâles chez la larve de Drosophile ont été décrites par Aвогм (1945). Khishin (1957) apporte cependant les précisions suivantes : au $3^{\mathrm{e}}$ stade larvaire (I $2^{\mathrm{e}}$ heure) il n'y a pas de signe indiquant le début de la méiose. Les spermatocytes primaires les plus anciens sont encore en interphase (stade d'accroissement). Environ $3 \mathrm{~h}$ après, au début de la prépupaison, quelques spermatocytes primaires se trouvent en prophase de première division méiotique.

Dans le second âge prépupal ( $\left(20^{\mathrm{e}} \mathrm{h}\right.$ ), les très petits spermatocytes secondaires commencent à apparaître dans le centre de la région postérieure du testicule. Au moment de la pupaison proprement dite $\left(126^{\mathrm{e}} \mathrm{h}\right)$ des faisceaux de spermatides déjà allongés peuvent s'observer aisément. A mesure que la pupe croît en âge, le testicule contient plus de spermatocytes secondaires et de faisceaux de spermatides que de spermatogonies et de spermatocytes primaires.

Quand le mâle parvient à l'émergence imaginale, ses testicules contiennent tous les stades de la spermatogenèse, à l'exception des spermatozoïdes mobiles. Ils apparaissent quelques heures plus tard (KHISHIN,I955). LüNING (1952) avait adopté le terme de "stade de maturation " pour qualifier l'état du testicule possédant des spermatides, et celui de " stade de maturité " pour désigner l'état du testicule possédant des spermatozoïdes. KHISHIN (I957) emploie le terme de "sperme en maturation " dans une acception légèrement différente : il concerne pour cet auteur, le stade qui va de la fin de la spermiogenèse jusqu'à ce que le sperme soit complètement mobile et physiologiquement mûr.

Les avis des auteurs diffèrent quant au moment de l'apparition de la méiose dans le testicule immature. Ainsi KAPLAN et Sisken (I960) ont fait ingérer de la thymidine tritiée incorporée à la nourriture, à des larves de Drosophile âgées de $16 \mathrm{~h}$. Utilisant une méthode autoradiographique, ils concluent que les spermatocytes doublent leur quantité d'ADN très tôt au cours de leur vie, puisque chez les larves d'âge compris entre 20 et $39 \mathrm{~h}$ la prophase méiotique a commencé. Le décalage de temps entre les résultats de KHISHIN et ceux de KaPLAN et SISKEN, provient pour une part de la différence des méthodes employées, également de l'utilisation d'une chronologie différente de développement et enfin au fait que l'autoreproduction de l'ADN s'effectue au stade préleptotène.

\section{Détermination de la durée de la spermatogenèse et de la spermiogenèse}

\section{A - Par la méthode autoradiographique.}

Chandlex et Bateman (1962) ont procédé à des autoradiographies par marquage de testicules de mâles de Drosophila melanogaster nouvellement parvenus à l'émergence, en utilisant la thymidine 
tritiée. Ils ont observé que 24 h après l'injection, "jour 1 ", les spermatogonies et les cystes de jeunes spermatocytes à l'extrémité proximale du testicule étaient marqués.

-- Aux jours 2 et 3 le marquage atteignait les spermatocytes en début de prophase méiotique, emplissant de plus en plus le testicule.

- Au jour 4 les chromosomes en diacinèse étaient marqués et les cystes des cellules marquées étaient à mi-chemin du ${ }^{\text {er }}$ des 2 tours de spires du testicule.

- Le $5^{\mathrm{e}}$ jour, des spermatides marqués dans le $\mathrm{I}^{\mathrm{er}}$ stade avec un noyau sphérique apparaissent pour la première fois.

- Le $6^{\mathrm{e}}$ et le $7^{\mathrm{e}}$ jour les spermatides marqués sont arrangés en paquets et subissent une condensation. Ie marquage devenant plus évident (chaque grand cyste étant formé d'un faisceau de 64 têtes de spermatozoïdes).

- $\mathrm{Au} 8^{\mathrm{e}}$ et $9^{\mathrm{e}}$ jour, les mêmes paquets marqués qui correspondent maintenant morphologiquement aux spermatozoïdes mûrs, sont trouvés dans la vésicule séminale.

- Le $10^{\mathrm{e}}$ jour, des spermatozoïdes marqués apparaissent pour la première fois dans les frottis d'éjaculats prélevés chez la femelle.

- Au $I_{1}{ }^{\mathrm{e}}$ jour, la fréquence des spermatozoïdes marqués est beaucoup plus grande, mais elle tombe brusquement le $\mathrm{I} 2^{\mathrm{e}}$ jour.

Chandeey et Bateman concluent que la période qui va de la synthèse de l'ADN dans le spermatocyte jusqu'à la fécondation est de to jours chez les mâles accouplés sans interruption.

Dans cet intervalle, 4 jours sont utilisés pour la maturation du spermatocyte, 5 jours pour la spermiogenèse et I jour pour l'aptitude à la fertilité. (Ce qui correspondrait au stade de "sperme en maturation " reconnu par KHISHIN (1957).

\section{B - Par l'utilisation des irradiations.}

Postérieurement aux travaux de Harris (I929), Hanson et Heys (I929) Timoféeff-Ressovsky (1930, i93 I) et de Shapiro (193I), Demerec et Kadfmann (194I) ont déterminé le temps minimum au bout duquel, des mâles âgés de 6 jours, ayant subi un traitement à $3000 \mathrm{r}$ peuvent recouvrer des spermatozoïdes : habituellement $c^{\prime} e s t$ le $19^{\mathrm{e}}$ jour après le traitement, avec possibilité éventuelle d'une production de spermatozoïdes dès le $\mathrm{i} 2^{\mathrm{e}}$ ou le $\mathrm{i} 3^{\mathrm{e}}$ jour.

La durée de la spermatogenèse déterminée par ces auteurs, ne correspond pas au temps donné par Chandeley et Bateman (1962). Le temps obtenu par la méthode autoradiographique ne correspond pas à la durée complète de la spermatogenèse puisqu'il ne fait pas intervenir celui concernant l'évolution des cellules germinales antérieures au stade pré-leptotène, temps pendant lequel les cellules germinales peuvent avoir été lésées lors des irradiations. MandL (rg64) indique que la durée de la spermatogenèse peut ne pas être exactement la même après une irradiation que dans un testicule normal. Nous venons d'en avoir une confirmation toute récente par les travaux de MARTIN (1965) (1) que nous examinerons dans le paragraphe suivant.

En vue d'étudier de manière très précise la sensibilité différentielle du sperme irradié à différents stades de la spermatogenèse, Auerbach (I954), puis Mossige (I955) ont élaboré un procédé pour que le système d'accouplement adopté permette le maximum d'utilisation de tous les spermatozoïdes mûrs chez le mâle afin d'éviter le chevauchement dans le temps de spermatozoïdes normaux et de spermatozoïdes provenant de cellules irradiées. Mossige (I955) irradie des mâles à $2500 \mathrm{r}$ dès l'émergence, puis place chacun avec 8 femelles par jour pendant les 3 premiers jours, et avec 5 femelles par jour les jours suivants. MosSIGE a constaté que les mâles traités présentent une très faible fréquence d'accouplement et une baisse importante de fécondité le $8^{\mathbf{e}}$ et le $9^{\mathrm{e}}$ jour après l'irradiation. Enfin elle enregistre une augmentation des létaux dominants du $6^{\mathrm{e}}$ au $9^{\mathrm{e}}$ jour après l'irradiation. Elle assiste ensuite à une reprise de la fertilité chez les femelles fécondées par ces mâles. L'irradiation dès l'émergence a donc lésé des stades précoces de la spermatogenèse et il a fallu 6 à 9 jours pour

(1) Signalons également une publication toute récente de TrauT, I966. 
qu'ils parviennent au stade spermatozoïdes porteurs de chromosomes lésés. Ces chiffres sont ici en accord avec ceux donnés par Chandey et BATEMAN (1962) utilisant la méthode autoradiographique.

\section{C. - Par l'emploi des deux méthodes combinées.}

A la suite d'une étude critique détaillée, MarTin ( 1965$)$ est parvenu à établir tout d'abord que la durée de la spermatogenèse n'est pas la même selon qu'il s'agit de testicules immatures (larves traitées à la thymidine tritiée) ou de testicules mûrs (mâles adultes). Il y a un retard de 24 heures chez les premiers par rapport aux seconds. Ensuite MARTin donne une table chronologique montrant un décalage de 24 heures dans la durée de la spermatogenèse chez les nâles irradiés par rapport à celle des mâles témoins. Ce retard serait induit par les rayons $\mathrm{X}$.

Dans ce cas, le sperme mûr apparaît au $8^{e}$ jour après marquage chez les témoins non irradiés, alors que chez les mâles irradiés, il n'apparaît que le $9^{\mathrm{e}}$ jour.

\section{Rythme de la spermatogenèse (cinótique de la production des spermatozoïdes).}

Tinen (I946) essaya d'estimer le nombre de divisions des cellules ancestrales (allant des cellules germinales primordiales jusqu'à la formation des spermatocytes primaires) car cette question était confuse, mais son estimation s'avère fausse car il s'inspire de données inexactes au départ : il se basait sur le fait qu'un mâle vigoureux produit au moins 10000 à 14000 descendants (ceci d'après les résultats de Duncan (1930). Des travaux plus récents (Hannah-Alava, 1964) montrent tout au moins sur une période de 24 jours, que la production est loin d'atteindre cette valeur. Il est donc difficile de connaïtre ce nombre de descendants car il est sujet à variation : il est fonction de la souche utilisée et fonction de la durée de vie du mâle, elle-même très variable d'un mâle à l'autre.

Par ailleurs Tihen se basant sur les travaux de Kaufmann et Demerec (1942) pensait qu'une femelle utilisait 20 à 30 spermatozoïdes par œuf fécondé. Il fallait donc que quelques 200 à 400000 spermatozoïdes soient produits, soit roo à 200000 dans chaque testicule pendant la période fertile. Or, comme nous le verrons, la polyspermie n'intervient pas ou rarement. TiIIEN ne tient pas compte dans son calcul de l'inévitable gaspillage des gamètes mâles, survenant dans les voies génitales femelles lors de la mise en réserve et qui est de l'ordre de 80 p. ros des gamètes primitivement. déposés dans l'utérus.

On voit donc combien sont fragiles de pareilles estimations à partir de telles données, il aboutit en effet à $12 \mathrm{I}$ divisions ancestrales précédant la formation du $75000^{\mathrm{e}}$ spermatozoïde, en partant d'une moyenne de 150000 spermatozoïdes produits par I testicule pendant la période fertile. Ce qui est manifestement exagéré. TiHEN conclut donc qu'un écart approximatif de 200 générations cellulaires est susceptible d'exister entre les premiers et les derniers spermatozoïdes produits par un mâle. De ceci il faut cependant retenir que si tout spermatozoïde mûr a toujours le même âge physiologique, il n'en esst pas de même de son âge cytologique et les estimations de Tinen ont montré que les spermatozoïdes produits par un mâle tout au long de sa vic différaient les uns des autres quant à leur âge cytologique : ils appartiennent à des générations cellulaires seccessives. Ce problème n'a pas été repris depuis de façon plus précise (1).

On considère généralement que le processus de la spermatogenèse est continu chez la Drosophile depuis le stade pupal jusqu'à la fin de la période fertile chez l'adulte (PHILIP, I942). En conséquence des spermatozoïdes nouvellement formés viennent périodiquement remplacer ceux qui sont utilisés par le mâle au cours des accouplements successifs. C'est-à-dire que la première réserve, prête avant l'émergence, se renouvelle, après épuisement, un certain nombre de fois.

Tinen (I946) émit une hypothèse pour expliquer le déroulement de la spermatogenèse dans le temps. Il suppose que les I I cellules germinales primordiales qui entrent dans le testicule dans les premiers stades embryonnaires, se comportent comme des cellules "cambiales". Elles se divisent périodiquement : chaque cellule cambiale donne naissance au spermatogonium définitif, qui à son tour subit 4 divisions mitotiques précédant la formation des spermatocytes de $\mathrm{I}^{\mathrm{er}}$ ordre, et 2 divisions

(1) Nous apprenons en cours d'impression deux publications d'Åbro $(1965, a, b)$. 
méiotiques, donnant ainsi 64 spermatozoides. Comme il suppose que toutes les cellules "cambiales " se divisent périodiquement, toutes en même temps chaque génération cambiale produirait :

$$
\text { I } \times 64=704 \text { spermatozoïdes. }
$$

Ils s'accumulent dans les voies génitales mâles jusqu'au ${ }_{\mathrm{I}}^{\text {er }}$ accouplement. Nous admettons donc l'idée d'une division régulière d'un cambium, c'est-à-dire l'existence de cystes à toutes les phases. de la spermatogenèse, étant donné que chaque cyste produit 64 spermatozoïdes, la discontinuité entre la formation de 2 cystes appartenant à 2 phases seccessives, sera faible et donc peu perceptible.

On peut envisager que le rythme de la spermatogenèse, c'est-à-dire la maturation des cystes. se fasse soit à vitesse constante (on aura donc une production continue et régulière de spermatozoïdes). ou bien à vitesse variable et dans ce cas, on assisterait à un ralentissement de la production des spermatozoïdes, car le cas d'une accélération de la spermatogenèse n'a jamais été observé dans les conditions naturelles : la proportion des spermatocytes en maturation et des spermatides est la même chez les mâles accouplés sans interruption et chez ceux qui sont gardés vierges jusqu'au roe jour (CHANDLEY et Bateman, 1962). Ce n'est que dans des conditions expérimentales particulières (choc thermique à $+36^{\circ} \mathrm{C}$ pendant ${ }_{15}$ minutes) qu'il a été envisagé une accélération de la spermatogenèse par IYENGAR et BAKER ( 1962$)$.

Si l'on considère la production continue on peut avoir les diverses possibilités suivantes :

a) Utilisation immédiate par le mâle des spermatozoïdes au cours des accouplements journaliers. Selon Chandley et Bateman (I962), tous les spermatozoïdes sont éjaculés à mesure qu'ils sont mûrs.

b) Possibilité d'une accumulation des spermatozoïdes dans les vésicules séminales si le mâle n'est pas admis à s'accoupler, au moins pendant quelques jours. C'est l'opinion d'un certain nombre d'auteurs dont Mossige (I955), Lefìvre et Jonsson (1962, c).

c) Résorption et/ou éjaculation, chez les mâles maintenus vierges, hypothèse à laquelle parviennent LÜNING (I952), MCSheEHy (I963), Mossige (1955).

Par contre, si l'on considère l'éventualité d'un ralentissement de la spermatogenèse il peut avoir 2 causes :

a) Il peut être une conséquence du vieillissement du mâle : on sait que la fécondité diminue régulièrement en fonction du temps.

3) Il peut provenir du fait que le mâle soit maintenu vierge pendant une plus ou moins grande partie de sa période fertile : c'est une conclusion possible à laquelle on parvient d'après l'examen des travaux de Mossige (1955) selon laquelle la fécondité mâle n'augmente pas avec le temps de privation des femelles (davantage de spermatozoïdes devraient s'accumuler dans les vésivules séminales au bout de $\mathrm{I}_{3}$, I7 et $2 \mathrm{I}$ jours). Mais on peut aussi penser qu'il y a tuut simplement résorption.

Nous voyons que ces diverses possibilités sont contradictoires, mais il semble que les résultats des auteurs le sont également.

Pour Sigot (1953) le mâle utilise des spermatozoïdes de nouvelle formation plus ou'moins tôt, selon que les accouplements se seront succédés à un rythme plus ou moins rapide. Cet auteur étudia un problème dans un domaine tout différent (celui du pourcentage de Drosophiles sensibles au gaz carbonique engendrées par des individus sensibles après croisement à des conjoints résistants) la valeur de ce pourcentage étant alors caractéristique d'un mâle, a reçu le nom de "valence ", SIGOT a été amené à enregistrer une variation, en quelque sorte cyclique de la valence des mâles en fonction du temps. Il est ainsi parvenu à déterminer le jour à partir duquel un nouveau " lot " de spermatozoïdes est utilisé.

$\mathbf{I}^{\mathbf{o}}$ Lorsque le nombre de femelles offertes au mâle est faible $(\leqslant 2)$, l'épuisement de $\mathbf{I}^{\text {re }}$ réserve est relativement lent $:$ il n'est achevé que le I $3^{\mathrm{e}}$ jour de la vie du mâle.

$2^{\circ}$ Quand le nombre de femelles est compris entre 4 et io, l'épuisement de cette $\mathrm{I}^{\mathrm{re}}$ réserve est plus rapide et accompli dès le $9^{\mathbf{e}}$ jour.

Dans ce cas, il semblerait donc que l'on puisse déceler les différentes " vagues " de production des spermatozoïdes, alors qu'elles devraient se succèder de façon continue, en rapport avec ce que nous avons dit au cours de ce paragraphe. 
LÜNING (1952) prétend que si les mâles ne sont pas admis à s'accoupler, le sperme mûr est résorbé et/ou éjaculé sans copulation. Cette affirmation ne s'appuie cependant sur aucune preuve cytologique. Cet auteur pense qu'à l'intérieur des testicules de ces mâles maintenus vierges, il n'y a pas mélange de spermatozoüdes qui ont mûri à des temps différents (loc. cit.). LüNing n'admet donc pas qu'il puisse y avoir accumulation dans les voies génitales comme le pense par contre Sigot qui affirme que les spermatozoïdes produits par vagues successives, se trouvent mélangés dans les testicules et les voies génitales où ils s'accumulent jusqu'au I er accouplement.

Fn résumé, on ignore s'il y a accumulation importante ou non des spermatozoïdes dans les voies génitales mâles; LEFìvRE et Jonsson ( $1962, c)$ inclineraient à penser, comme nous le verrons au paragraphe suivant, qu'une certaine accumulation s'effectue. Par ailleurs, on ignore s'il y a ou non, une relation entre le rythme de production des spermatozoïdes et leur utilisation. LüNING (1952) laisse supposer que ces 2 phénomènes sont totalement indépendants.

Il semble donc que ce problème ne soit pas encore résolu et qu'il demande à être repris en utilisant les méthodes autoradiographiques en marquant les cellules sexuelles mâles par des précurseurs d'ADN et en suivant dans le temps, l'évolution du front de marquage tant chez les mâles admis à copuler que chez les mâles maintenus vierges.

\section{Progression dans les voies génitales mâles}

Quand le sperme est mûr, les spermatozoïdes passent donc à l'intérieur des vésicules séminales dans lesquelles ils ne se présentent plus en faisceaux. La lumière de chaque vésicule se remplit d'une masse de spermatozoïdes densément entassés. Les spermatozoïdes ne sont pas mobiles au niveau des testicules, mais au niveau de la vésicule séminale où leur mouvement peut être facilement observé (LeFìvre et Jonsson, I $962, c$ ). Ce fait semble bien être particulier à la Drosophile, car pour les autres groupes d'Insectes, DE WILDE (I964), DAVEY (1965), signalent que les spermatozoïdes migrant dans la vésicule séminale sont immobiles. Leur mobilité réduite étant due à la rareté du liquide séminal ou à des substances inhibitrices sécrétées par la paroi de la vésicule séminale (PAvNe, 1933, in DE Wilde, 1964). DE WILDE signale que lorsque les spermatozoïdes sont dilués dans des solutions salines ou dans la partie liquide de l'éjaculat leur motilité est grandement augmentée [BISHor (I920), Blum et al. (1962) in DE WiLde (1964)].

Après dissection dans du liquide de Ringer et en rompant les vésicules séminales, LEFèvre et Jonsson $(\mathrm{Ig62}, c)$ ont observé la libération des spermatozoïdes et une intense motilité. Par contre, dans les mêmes conditions, les spermatozoïdes en faisceaux, libérés du testicule, restent totalement immobiles. Ces mêmes auteurs ont abordé l'étude de la progression des spermatozoìdes des testicules vers les vésicules séminales. Les résultats préliminaires suggèrent que le processus de l'émission est continu plutôt qu'intermittent. Les vésicules étant douées d'élasticité, elles augmentent progressivement de volume, à mesure que de nouveaux spermatozoïdes en maturation pénètrent et se mélangent à ceux qui ont mûri plus tôt. Ceci vient à l'encontre de la conclusion de LüNing (I962) que nous avons déjà relatée.

\section{Ejaculation}

Les premières observations fondamentales sont dues à NonIdEz (I920). Il explique la propulsion du sperme à travers le tractus génital mâle grâce à l'action du bulbe éjaculateur, organe qui fonctionne comme une pompe, chassant ainsi le sperme à forte pression à travers l'étroit canal éjaculateur.

L'éjaculation prend place environ 9 à to minutes après le début de la copulation (qui elle-même dure en moyenne une vingtaine de minutes).

Selon cet auteur, les spermatozoïdes après éjaculation dans "l'utérus " apparaissent immobiles, seulement un très petit nombre montrant de vagues mouvements ondulatoires, ceci durant 2 à 3 minutes. Puis après ce délai ces derniers se mettent à nager activement pour entrer dans le réceptacle séminal. NONIDEZ suppose que cette mise en activité est due à l'existence de sécrétion provenant d'une paire de glandes annexes (parovaria) en rapport avec la portion antérieure de l'utérus, et dont le rôle est encore assez énigmatique à l'heure actuelle. 
Mais les vues de Nonidez nous semblent partiellement erronées. Pour notre part, l'observation. in vitro d'organes génitaux de femelles tuées immédiatement après accouplement nous ont montré au contraire, au microscope à contraste de phase, une intense activité des spermatozoïdes dans. l'utérus. Ce qui paraît normal, puisque l'observation des vésicules séminales du mâle montre déjà. des spermatozoïdes mobiles.

\section{Chapitre II \\ Physiologie SEXUELIE DU MALE}

Nous ne traiterons pas ici le problème du comportement sexuel du mâle, sortant de l'objet de notre étude, nous renvoyons le lecteur aux publications de Bastock et Manning (1955), d'HoenigsBerg (1960), d'IIoenigsberg et SANTibanez (i960) où les détails de la parade nuptiale (orientation. du mâle par rapport à la femelle, vibration des ailes et léchage) sont décrits. Nous n'aborderons pas non plus le problème de la compétition sexuelle chez les différents mutants du mâle de la Drosophile, dont le déterminisme génétique a été étudié par Petrit (1958).

\section{Acquisition de la maturité sexuelle}

STRÖMNAES et KVELland ( 1962 ) précisèrent les premiers le moment à partir duquel le mâle est capable d'être fécond. Les mâles nouvellement émergés, ne s'accouplent ordinairement pas avant qu'ils n'aient atteint leur maturité : soit un âge de $12 \mathrm{~h}$ environ. Ceci est en relation avec l'état des testicules, ainsi que nous l'avons vu chapitre premier. Cependant les accouplements peuvent survenir avant ce délai, mais 75 p. Ioo de ceux-ci, accomplis par des mâles âgés de 7-8 heures, sont stériles. Quand les mâles sont âgés de $\mathrm{I} 3$ heures, cette fréquence tombe à $\mathrm{I} 3$ p. I00. La fécondité des mâles augmente donc avec l'âge, mais les auteurs concluent avec prudence, que seulement une petite proportion des mâles atteint la maturité sexuelle dans les I 2 premières heures. Dans les expériences de croisements, on mesure alors l'intérêt de l'isolement des femelles moins de 5 heures après leur émergence, si l'on veut qu'elles soient vierges, puisque 6 heures après la sortie de la pupe, déjà I p. roo. des mâles ont copulé.

\section{Variation de la fécondité au cours du temps}

\section{A - Nombre de femelles non limité.}

a) Fréquence des accouplements.

Strömaes et Kvelland (1962) indiquent, tout au moins pour les 4 premiers jours de la vie du mâle ( $\left.{ }^{1}\right)$, que la fréquence de copulations la plus forte pendant une heure, pour des mâles respectivement âgés de $2 \mathrm{~h}, 24,72$ et $96 \mathrm{~h}$, est trouvée chez les mâles âgés de $72 \mathrm{~h}$ sans atteindre un pourcentage de I00 p. Ioo mais seulement de 86 p. ıоo. Ces auteurs ont également étudié le nombre moyen d'accouplements chez de tels mâles. Il en résulte qu'il n'y a pas de différences significatives dans le nombre moyen d'accouplements pour les mâles "stériles ", que ces mâles aient $2 \mathrm{~h}$ ou $96 \mathrm{~h}$ d'existence. Par contre, ils ont remarqué que, pour les mâles fertiles, il existe une nette différence dans la capacité d'accouplement de ces derniers selon leur âge. Un mâle d'âge compris entre 0 et $24 \mathrm{~h}$ s'accouple en moyenne avec I, 4 femelles en I $2 \mathrm{~h}$, tandis qu'un mâle âgé de 24 à $48 \mathrm{~h}$ s'accouple en moyenne avec $\mathbf{2 , 7}$ femelles et enfin un mâle d'âge compris entre 72 et 96 heures s'accouple en moyenne avec 5 femelles. Donc le nombre moyen de copulations augmente avec le temps mais les auteurs n'ont malheureusement pas poursuivi leur étude au-delà de la période de $96 \mathrm{~h}$.

STRömNaEs et Kvelland font également une nette distinction entre le comportement sexuel et la fécondité et montrent qu'une activité sexuelle élevée mène à une proportion d'accouplements

(1) Précisons qu'il s'agit de mâles ayant subi une irradiation de $2000 \mathrm{r}$ soit dans les 2 premières heures suivant l'émergence, ou bien $24 \mathrm{~h}$ ou enfin $72 \mathrm{~h}$ après. 
stériles plus importante. La fécondité mâle - que nous définissons comme étant le nombre de descendants produits - est prise par ces auteurs dans un sens différent puisque, c'est d'après eux, essentiellement le nombre de femelles fécondées. Mais ils estiment que la fécondité mâle ne peut convenablement être estimée seulement d'après ce critère : des mâles sexuellement plus actifs ont une plus forte fréquence d'accouplements stériles que les mâles sexuellement moins actifs. L'autre aspect que ces auteurs accordent à la définition de la fécondité étant bien le nombre de descendants produits. Strömnaes et KvelLand montrent qu'il y a une augmentation logique dans le nombre de descendants, en rapport avec l'accroissement de fréquence d'accouplement des mâles. Toutefois on comprendra que les femelles qui ont copulé avec des mâles sexuellement " très actifs " produisent en moyenne une moindre descendance que les femelles qui ont copulé avec des mâles moins actifs. Le nombre de descendants issu de chaque accouplement semble décroître avec l'augmentation de l'activité sexuelle du mâle.

Pour Kvelland ( 1965 a), la productivité mâle semble être maximum dans les 3 premiers jours de la vie du mâle, après quoi elle décroît régulièrement. Mais il est difficile de généraliser car l'auteur prend soin de dire qu'il y a de grandes variations individuelles dans la capacité d'accouplement, la fertilité et la fécondité du mâle.

\section{b) Nombre de descendants.}

DunCAN (1930) est un des rares auteurs qui ait étudié la "productivité " des mâles tout au long de leur vie, certains d'entre eux vivant un peu plus de 3 mois ( 99 jours), les autres ayant une durée de vie plus courte : $72,66,60,53$ et 43 jours (1). Il utilisa des mâles sauvages et des femelles Bar. Il est parvenu aux conclusions suivantes : la fécondité atteint son maximum durant les 5 premiers jours pour décroître à peu près régulièrement jusqu'au $3^{\circ}$ jour (la période fertile moyenne pour les mâles est de 32 jours) et à partir de ce moment-là il constate une notable diminution dans le nombre de descendants pour tous les mâles envisagés.

Toujours d'après cet auteur, le nombre total de descendants qu'un mâle peut engendrer va, selon les mâles, de 7368 à 14 070, soit une moyenne de 1o 7 I9 descendants.

Hannah-Alava et Puro (1964) ont étudié la fécondité de 35 mâles répartie sur 24 jours en recueillant le nombre de descendants issus de lots successifs journaliers à raison de 7 femelles par mâle pendant les 7 premiers jours et ensuite de 5 femelles par mâle pendant les jours suivants.

Ces auteurs ont mis l'accent sur la nécessité d'observer une certaine proportion femelles/mâle par tube. Ils ont montré que la fécondité diffère selon les proportions de femelles mises en présence de chaque mâle et dans le traitement des femelles après transfert du mâle. C'est surtout dans la période des 7 premiers jours que la proportion des femelles mises à la disposition des mâles affecte la fécondité.

Ces auteurs ont obtenu avec 35 mâles un total de I 39308 descendants, soit une moyenne de 3980 mouches par mâle. Il ressort que le nombre de descendants décroît régulièrement avec l'augmentation de l'âge des mâles.

Ils signalent également qu'une stérilité sporadique peut survenir certains jours, la fécondité reprenant le jour suivant.

Un mâle ne donne cependant pas plus de descendants lorsqu'il est placé en présence de 50 femelles pendant 24 heures, que si on lui fournit seulement 5 femelles, en d'autres termes le mâle ne copule pas indéfiniment (Lefevre et Parker, I963). Ces auteurs pensent avec juste raison que le mâle passe par un temps de repos pendant lequel ses glandes accessoires se rechargent en sécrétion. C'est la cause de la stérilité naturelle survenant après 4 ou 5 accouplements successifs en $\mathrm{i} 2 \mathrm{~h}$ ( 5 copulations effectives paraissent être pour ces auteurs le maximum réalisé par I mâle journellement). Toutefois dans l'expérience de Lefevre et Parker l'âge des mâles utilisés n'est pas indiqué, ce qui serait utile de connaître, la fécondité du mâle étant fonction de l'âge. Ensuite les auteurs ne précisent pas combien

(1) La durée de la vie moyenne du mâle de $D . m$. serait de 38 , I jours pour la souche sauvage, d'après les données de Gonzalez, i923, in De Wilde, I964. 
il y a d'accouplements fertiles et stériles. En résumé, cette expérience nous fournit seulement un résultat global dont il est difficile de tirer des conclusions détaillées.

Ces auteurs sont du reste, en désaccord avec StrömnaEs et Kvelland (1962) qui prétendent que le mâle copule, quand bien même il n'ait pas de sperme à transférer. Ceci est normal chez les Insectes car le comportement sexuel et la fonction génitale sont indépendants l'un de l'autre (DE WiLDE, 1964).

En résumé, des mâles âgés de 3 jours peuvent copuler en moyenne 5 fois par jour (STRöunaEs et Kvelland, ig62 ; Lefkvre et Parker, 1963). Mossige (I955) donne le nombre de 10 femelles vierges par jour, fécondables par un mâle. L'unanimité n'est donc pas réalisée parmi les différents auteurs sur le nombre optimum de femelles à fournir à r mâle.

c) Influence de la densité de population sur l'activité sexuelle du mâle.

Del Solar (1964) a étudié l'effet de 2 paramêtres sur la fréquenece d'accouplement du mâle, à savoir : le volume du tube utilisé (variant de 10 à $40 \mathrm{~cm}^{3}$ ) et le nombre de paires de mouches mises en présence. Il en résulte que :

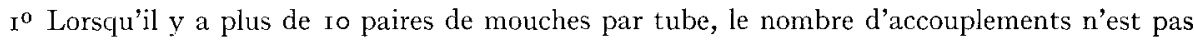
affecté par le volume offert, mais si le nombre de paires varie de i à 5, le nombre d'accouplements est significativement plus faible dans un volume de $40 \mathrm{~cm}^{3}$ que dans 10 ou $20 \mathrm{~cm}^{3}$.

$2^{\circ}$ Le délai avant l'accouplement décroît en relation avec l'augmentation du nombre de mouches, atteignant ensuite un minimum d'environ 6 minutes, le volume n'important pas.

\section{$\mathrm{B}$ - Fréquence d'accouplements en fonction d'un nombre déterminé de femelles.}

MCSheErry (1963) a observé que celle-ci augmentait avec le nombre de femelles: il a constitué 2 lots : l'un dans les proportions de I mâle/8 femelles et l'autre de I mâle/2 femelles : dans le premier lot la fréquence d'accouplements par femelle est $50 \mathrm{p} .100$ plus élevée que dans le $2^{\mathrm{e}}$ lot $:$ autrement dit, lorsqu'il y a peu de femelles leur période réfractaire limite le nombre d'accouplements. Mais, si le nombre de femelles augmente, un effet de compétition apparaît, et elles acceptent alors plus volontiers les mâles qui effectuent ainsi un nombre beaucoup plus grand de copulations. Il y a là un fait intéressant à retenir pour tenter d'obtenir plus facilement des réaccouplements dans les expériences de doubles-copulations, où les femelles prises isolément se montrent totalement réfractaires pendant au moins 4 jours, ainsi que l'a montré MANNING (1962 a).

\section{Divers types de stérilité}

Il y a lieu de distinguer dans la stérilité mâle, celle qui survient à la suite d'accouplements très rapprochés dans le temps, de celle qui est consécutive au vieillissement du mâle, celle qui survient sporadiquement et celle consécutive aux irradiations.

\section{A - Stérilité après copulations multiples.}

LEFEVRE et JoNSSON (1962 c) ont disséqué des mâles qui ont effectué 5 accouplements successifs dans une période de $3-4$ heures, ces auteurs ont alors montré que la baisse dans le nombre de spermatozoïdes transférés lors de chaque accouplement successif, n'était pas due à l'épuisement des vésicules séminales en spermatozoïdes, mais en relation avec l'état des glandes accessoires ; ces dernières sont complètement dépourvues de sécrétion. Les accouplements stériles enregistrés au-delà de 5 accouplements successifs, ont leur cause physiologique dans un épuisement des glandes accessoires.

\section{$\mathrm{B}-$ Stérilité et sénescence.}

A la suite de la période fertile, s'instaure chez le mâle une période sénile de 2 I à 34 jours avans la mort, selon les mâles (DUNCAN, 1930) mais qui varie certainement aussi selon les souches. Dans det préparations de coupes de testicules de mâles se trouvant dans cette période stérile, DUNCAN (I930) 
observe encore des figures mitotiques et des spermatozoïdes. Cet auteur n'impute pas la stérilité à un manque de spermatozoïdes dans les testicules, mais plutôt à une cause d'ordre mécanique : dans un défaut de fonctionnement de l'appareil éjaculateur puisqu'il prétend que les glandes accessoires fonctionnent encore normalement. L'argumentation de DunCAN n'est pas absolument convaincante, car dire que les spermatozoïdes sont produits, ne veut pas dire pour autant que ceux-ci soient actifs. On ignore du reste pourquoi les spermatozoïdes perdent leur pouvoir fécondant lors du vieillissement (cas de l'Homme par exemple).

Plus récemment, Hannah-Alava et Puro ( 1964$)$ ont repris ce problème de la stérilité survenant dans la période de 18 à 24 jours de la vie du mâle. Mais ces auteurs hésitent encore entre 2 hypothèses, à savoir : soit un déficit dans la sécrétion des glandes accessoires, soit à un ralentissement de la spermatogenèse. En fait, la cause réelle de cette stérilité n'est pas encore nettement démontrée.

\section{C - Stérilité sporadique.}

Le mâle de la Drosophile n'est pas forcément constamment fertile même s'il a atteint la maturité sexuelle.

DUNCAN (1930) compte 9,7 p. Ioo d'accouplements stériles durant la vie fertile du mâle. HannarrAlava et Puro (1964) signalent également qu'une stérilité sporadique peut survenir certains jours, la fécondité reprenant normalement le lendemain chez les mâles étudiés durant les 24 premiers jours de leur vie.

KvelLANI) ( $1965 a$ ) note une faible proportion de mâles ne s'accouplant pas entre le $6^{e}$ et le I $2^{\mathbf{e}}$ jour dans un groupe de non-irradiés.

Il y a lieu en effet de distinguer dans la stérilité sporadique 2 cas :

le mâle ne s'accouple pas,

ou bien le mâle s'accouple, mais il accomplit une copulation stérile.

Un même mâle peut passer successivement par ces deux états.

$\mathrm{D}$ - Stérilité consécutive aux irradiations.

On retrouve les 2 cas envisagés ci-dessus. Chez des mâles âgés de 3 jours recevant $2000 \mathrm{r}$ et soumis ensuite à des accouplements journaliers avec au moins ro femelles, KvELLAND ( $1965 a$ ) note que : la proportion des mâles ne s'accouplant pas est beaucoup plus élevée chez les mâles irradiés que chez les mâles non irradiés, plus particulièrement du $8^{\mathrm{e}}$ au Io $\mathrm{e}^{\mathrm{e}}$ jour après irradiation.

Par ailleurs, les mâles irradiés ont montré une stérilité élevée du $9^{\mathrm{e}}$ au $\mathrm{II}_{\mathrm{I}}^{\mathrm{e}}$ jour, due principalement à des accouplements stériles, les mâles retrouvant leur fertilité le $\mathrm{I} 2^{\mathbf{e}}$ jour. Ce résultat correspond à ceux obtenus par de précédents auteurs : MOSSIGE (1955) notamment.

\section{Stockage et résorption des spermatozoïdes}

Les avis diffèrent selon les auteurs sur le problème de savoir s'il y a stockage ou non des spermatozoïdes chez les mâles maintenus vierges.

\section{A - Partisans du stockage.}

BAKER et von HALLE (I953) constatant la réparation des ruptures chromosomiques dans certaines conditions, à la suite d'expériences d'irradiation, supposent que de tels spermatozoïdes sont stockés avant que les mâles ne soient admis à copuler. Mossige (1955) prétend qu'un mâle maintenu vierge depuis l'émergence a toujours suffisamment de sperme disponible pour féconder environ 8 femelles durant les premières 24 heures d'accouplement sans égard à son âge (qu'il soit de 3,13, I 7 ou 2 I jours).

\section{B - Partisans de la résorption ou de l'élimination.}

LÜNING (I952, 1954) n'admet pas la possibilité de la mise en réserve du sperme et prétend qu'il est résorbé et/ou éjaculé sans copulation. MCSHEEHY $\left(19^{6} 3\right)$ conclut également qu'il y a une large résorp-

Annales de Biologie animale. - 1966. 
tion des spermatozoïdes chez les mâles maintenus vierges. Il est difficile de cenclure : l'observation de LüNING (1952) que nous avons rapportée plus haut (rythme de la spermatogenèse) est assez troublante mais l'auteur ne donne quand même aucune preuve expérimentale dírecte de la résorption.

Enfin relativement à l'expérience de Mossrge que nous venons de citer, force nous est de conclure que si la fécondité du mâle n'augmente pas avec le temps de privation des femelles, c'est que :

- Ou bien la spermatogenèse est ralentie (on ignore encore le mécanisme de rétro-contrôle qui serait imputé). Notons qu'un mécanisme de feed back a été invoqué chez Arenicola marina L. (Howie et McClenagiran, 1965).

- Ou bien les spermatozoïdes seraient résorbés (les vésicules séminales libéreraient l'excédent de spermatozoïdes les plus anciennement formés pour recevoir les plus récents).

En résumé, deux alternatives sont possibles selon que les auteurs admettent ou non qu'il y a une relation entre la production et l'utilisation des gamètes mâles.

\section{Rôle des glandes accessoires (paragonia) chez le mâle}

\section{A - Rôle principal.}

Nous avons vu précédemment que l'absence de sécrétion de ces glandes semblait être la cause de la stérilité naturelle des mâles survenant à la suite d'accouplements répétés (LEFEVRE et Jonsson, 1962 c). Plus récemment encore, Garcia-Bellido (ig64) ayant utilisé des mâles " épuisés » à la suite de copulations multiples, parvient aux mêmes conclusions : la sécrétion des paragonia apparaît être nécessaire au transfert des spermatozoïdes. NonIDEZ (I920) avait déjà présumé ce rôle de véhicule des spermatozoildes. Cette sécrétion fournissant la partie liquide de l'éjaculat. Cette fonction n'est cependant pas assurée par ce même organe chez les autres Diptères. KeUchenius (Igi3) montre que ces glandes paires sont absentes chez Musca corvina, Dexia canina, et Leptis scolopacea, leur fonction est alors assurée soit par les voies déférentes, soit lepar] canal éjaculateur, soit par les deux à la fois.

\section{$\mathrm{B}-$ Conséquences.}

L'expérience qu'a fait GotTscirewski (1937) montre que la sécrétion des paragonia semble être essentielle pour une fécondation effective : il prélève des spermatozoïdes dans la vésicule séminale du mâle et les injecte dans le vagin des femelles.

Il enregistre alors un faible pourcentage d'œufs fécondés chez de telles femelles, par contre, lorsque c'est l'éjaculat qui est artificiellement transféré du vagin de femelles venant de copuler, vers les femelles en expérience, les mouches produisent alors davantage de descendants.

\section{$\mathrm{C}$ - Autres rôles envisagés par les auteurs.}

GARCIA-BELLIDO (1964) suppose que cette sécrétion intervient également pour la mise en mouvement des spermatozoïdes à la sortie des vésicules séminales. Il va même jusqu'à supposer qu'elle agirait comme stimulus pour l'ouverture de ces vésicules séminales chez le mâle.

\section{$\mathrm{D}$ - Étude de la nature chimique de la sécrétion.}

Des substances libres, ayant une réaction positive à la ninhydrine, allant de pair avec des différences sexuelles, ont été signalées par plusieurs auteurs chez les Diptères.

Notamment Fox $\left(195^{6} a, b\right)$ dans son étude des acides aminés libres et des peptides chez Drosophila melanogaster, enregistre la présence de peptides chez le mâle mais non chez la femelle.

Chen et DiEM (196I) ont mis au point une méthode chromatographique adéquate pour démontrer la présence de ces peptides. Les paragonia de mâles adultes de $D$. melanogaster, contiennent une substance ninhydrine $(+)$ qui, de par sa position sur le chromatogramme à 2 dimensions, correspond au " peptide sexuel " rapporté par Fox ( $\left.195^{6} a, b\right)$. Ils constatent que, au cours de la croissance des glandes accessoires, durant les 5 à 9 jours après l'émergence imaginale, les glandes s'enrichissent corrélativement en sécrétion. 
Deux faits indiquent que cette substance apparaît seulement dans les paragonia du mâle :

a) Le prélèvement et l'analyse de l'intestin, des testicules, des paragonia et du canal éjaculateur provenant de 30 à 50 individus, mont rent que la substance apparaît exclusivement dans les paragonia.

b) On sait que chez la Drosophile, les conduits génitaux ainsi que les glandes accessoires et les genitalia externes se développent à partir d'un disque génital (HADORN, I949; BodensteIn, I950). Après la transplantation de disque génital mâle dans des larves de même sexe, CHEN et DIEm (196r) observèrent que la concentration de cette substance chez les adultes était sensiblement le double par rapport à celle trouvée chez les mâles témoins n'ayant pas subi de transplantation durant leur $3^{\text {e }}$ stade larvaire.

Par ailleurs, le fait que cette substance est trouvée aussi chez les femelles qui ont reçu un disque génital mâle par transplantation, indique que sa formation est autonome.

\section{ChAPITRE III}

\section{INFLUENCE DE DIVERS FACTEURS}

\section{Facteurs génétiques}

\section{A - Relation entre durée d'accouplement el génotype.}

Le temps moyen d'accouplement est de 20,8 minutes chez D. $m$. (Duncan, i93o). Cependant Manning (I96I) montre les effets de la sélection artificielle sur la durée d'accouplement. Il croise une lignée "lente " ( 80 minutes représentant la durée moyenne d'accouplement pour 50 couples) et une lignée rapide (3 minutes seulement). Il obtient des hybrides chez lesquels la durée d'accouplement est intermédiaire entre celle des 2 lignées ci-dessus.

Plus récemment encore plusieurs auteurs ont repris le problème: PARSONS (rg64) $\left(^{1}\right)$ montre que chez quelques lignées pures et hybrides de D. melanogaster, l'accouplement s'effectue avec des vitesses différentes. Il en déduit que la constitution génotypique exerce une action très importante sur la vitesse d'accouplement. Il est regrettable toutefois que cet article ne donne guère de précisions sur les lignées employées.

SPIESS et LANGER (I964) étudient le contrôle de la vitesse d'accouplement en fonction de l'arrangement des gènes du chromosome III chez des homozygotes de Drosophila pseudo-obscura. Les combinaisons géniques qui apparaissent le plus fréquemment dans la population ancestrale ( $\mathrm{S} T$ et $\mathrm{A} R$ ) font que les porteurs s'accouplent le plus rapidement ( $80 \mathrm{p}$. Ioo dans l'heure). Par contre, les arrangements de gènes qui sont moins communs dans la nature (C H et T L) donnent une vitesse d'accouplements intermédiaire (45 p. I0o dans l'heure). L'arrangement relativement rare du couple de gènes ( $\mathrm{P} \mathrm{P})$ donne les plus basses vitesses d'accouplements (20 p. I00 en I heure). Ces résultats suggèrent, disent les auteurs, que des différences dans la vitesse d'accouplement peuvent être importantes dans le maintien du polymorphisme chromosomique dans les populations naturelles.

\section{B - Relation entre l'hétérozygotie et la vigueur des mâles.}

Partant de l'observation que des souches conservées depuis longtemps au laboratoire sont, sans conteste, plus homogènes que celles nouvellement constituées par des mouches capturées dans des populations naturelles, Bösıger (1960, I962, 1963) établit qu'il y a une relation entre la vigueur des mâles et leur degré d'hétérozygotie pour les systèmes polygéniques. Il montre que l'on obtient ainsi une augmentation spectaculaire du nombre de femelles fécondées par un mâle, en croisant 2 souches dont les mâles sont peu vigoureux, Si des mâles des souches "forked " et "sepia " fécondent respectivement $23,78 \mathrm{p}$. 100 et $28,31 \mathrm{p}$. 1oo de femelles, les 2 types de mâles hétérozygotes réciproques, fécondent 74,27 p. 100 et 78,43 p. I00 de femelles. Ces résultats sont confirmés par d'autres et font apparaître un effet d'hétérosis pour la vigueur des mâles.

(1) Signalons depuis : Parsons (1965); Mac Bean et Parsons (1966). 
A l'inverse, l'auteur montre que si l'on rend une souche de plus en plus homogène, on constate au contraire une diminution notable de la vigueur des mâles. Il cite en exemple que les mâles d'une souche " cinnabar " qui fécondaient au départ 84,84 p. 100 de femelles ne fécondaient plus que $54,39 \mathrm{p}$. Ioo de femelles après 40 générations de croisements consanguins frère par sœur.

\section{Facteurs expérimentaux}

A - Action des rayons $X$.

a) Elle comprend le problème des mutations et de la radiosensibilité des divers stades. Nous nous contenterons de livrer quelques conclusions succinctes:

- le sperme mûr a un taux de mutation élevé ; par ailleurs la mutabilité du sperme mûr augmente de façon importante avec le temps (LEFEVRE et JoNSSON, I964).

- contrairement à l'opinion émise par OsTer (196I) la mutabilité des spermatozoïdes mûrs n'est pas affectée par le site de leur irradiation : que ce soit dans les vésicules séminales du mâle ou dans le réceptacle ventral et les spermathèques de la femelle (LEFEVRE et Jonsson, r964). Ces auteurs mettent l'accent sur le rôle protecteur que pourrait avoir la sécrétion des glandes accessoires du mâle. Enfin ces mêmes auteurs recherchent actuellement la mutabilité des différents stades de spermatides, et, contrairement à l'opinion générale, ils affirment que les spermatides au stade terminal ont une faible mutabilité, par contre, les spermatides dans leur phase initiale montrent une haute mutabilité imputée jusqu'alors aux spermatides indistinctement.

b) Cette action des rayons $\mathrm{X}$ exerce des répercussions physiologiques sur les spermatozoïdes eux-mêmes, et secondairement sur l'activité du mâle.

Yanaers (1964) montre en effet que, jusqu'à présent, on n'a pas assez tenu compte de l'état physiologique du spermatozoïde irradié, pour ne s'être attaché qu'à l'observation des effets génétiques provoqués par les rayons $\mathrm{X}$. Il conclut à une nette corrélation entre la baisse enregistrée dans le succès d'insémination et la dose administrée en kilo-rœntgens. 11 pense qu'un certain aspect du comportement des spermatozoïdes, la motilité peut-être, est affectée par les rayons $\mathrm{X}$ aux doses habituellement employées dans les études de génétique (jusqu'à $10000 \mathrm{r}$ ). Cette notion est nouvelle par rapport aux opinions émises jusqu'alors, à savoir qu'un sperme faiblement irradié n'était pas affecté dans sa motilité, ni dans sa survie.

A $10000 \mathrm{r}$ le sperme subit des dommages physiologiques aussi bien que génétiques. A des doses plus élevées : 25000 et $50000 \mathrm{r}$, la plupart des spermatozoïdes sont, soit tués, soit inactivés.

\section{$\mathrm{B}-$ Action de la chaleur.}

Nous citerons d'abord des travaux récents comme ceux d'Iyengar et Baker (1962). Ils soumettent des lots de mâles à $+36^{\circ} \mathrm{C}$ pendant ${ }_{5}$ minutes immédiatement avant accouplement. Un choc thermique semble augmenter plutôt qu'endommager la fécondité du mâle (il y a 30 p. Ioo d'accroissement de la descendance par rapport à celle donnée par les mâles témoins). Ces auteurs invoquent séparément ou simultanément les facteurs suivants :

$I^{0}$ spermatogenèse accélérée ;

$2^{\circ}$ nombre de spermatozoïde plus grand par éjaculat;

$3^{\circ}$ motilité accrue des spermatozoïdes tant chez le mâle que dans les voies réceptrices femelles.

Nous pensons qu'il faut voir là une action tout à fait limitée dans le temps, qui provoquerait une activation du métabolisme cellulaire, ou une variation passagère des propriétés physiques de la partie liquide de l'éjaculat (comme la viscosité par exemple).

Par contre, l'hypothèse d'une accélération de la spermatogenèse nous paraît douteuse : on comprend mal, comment l'élévation de température, précédant immédiatement l'accouplement, aurait le temps de mofifier le rythme de la spermatogenèse.

Cette action très fugace de la température re peut en rien être comparée à des travaux beaucoup 
plus anciens, comme ceux de Young et Plovgh (I926), où les auteurs soumettent les Drosophiles à des températures moins élevées mais durant plusieurs jours. Voici leurs conclusions :

I. Une température de $31^{\circ} \mathrm{C}$ a un effet différentiel sur les cellules sexuelles tel que $96 \mathrm{p}$. roo des mâles peuvent être rendus complètement stériles, tandis que $50 \mathrm{p}$. roo des femelles sont encore totalement fertiles.

2. Cet effet sur les mâles est durable aussi longtemps que cette température est maintenue, mais la plupart des mâles retrouvent une fertilité normale après avoir été replacés à $24^{\circ} \mathrm{C}$.

3. L'examen des testicules des mâles stériles montre qu'une haute température cause une perte de la motilité des spermatozoïdes avec agrégation progressive et dégénération. On ne trouve pas, on très peu de spermatozoïdes à la base du testicule et des canaux déférents.

4. L'aptitude à la copulation n'est nullement affectée, mais aucun spermatozoïde ne passe dans le réceptacle ventral de la femelle, quand les mâles sont maintenus à $3 \mathrm{I}^{\circ} \mathrm{C}$.

Ces travaux mériteraient d'être repris d'une façon plus approfondie. D'après DAvid (non publié) la stérilité totale chez le mâle est acquise dès $30^{\circ} \mathrm{C}$. Cet effet est réversible si l'on replace les mâles à une température de $25^{\circ} \mathrm{C}$.

\section{$\mathrm{C}-$ Action du froid.}

BAKer (1960) en soumettant des mâles et des femelles à $6^{\circ} \mathrm{C}$ pendant $60,7^{2}$ ou 80 heures enregistre une baisse de la descendance allant jusqu'à 67 p. I0o chez les femelles accouplées après ce traitement par rapport au groupe de contrôle.

IYENGAR et BAKER ( 1962 ) ont étudié également l'effet d'un choc par le froid en soumettant des lots de mâles à $-8^{\circ} \mathrm{C}$. Ils constatent qu'un tel choc endommage l'activité, donc la fertilité du mâle (il y a une diminution de 66 p. roo dans la descendance par rapport au groupe de mâles non traités par le froid). Le pourcentage de femelles non fécondées atteignait 7 r,4 p. I00 en utilisant des mâles soumis au froid, contre $27, \mathrm{I}$ p. I00 avec des mâles témoins.

LEFEVRE et JoNsSON $(\mathrm{I} 962, b)$ exposent des mâles à une température de - $10^{\circ} \mathrm{C}$ pendant to minutes et constatent que ce traitement rend inactifs tous les spermatozoïdes complètement mûrs et mobiles stockés dans les vésicules séminales du mâle. L'effet obtenu est identique en soumettant au froid des femelles récemment fécondées.

Ces auteurs ont également combien l'action des rayons $\mathrm{X}$ : les mâles sont d'abord irradiés à $4000 \mathrm{r}$ puis exposés au traitement réfrigérant : ils obtiennent alors une stérilité complète, avec peu ou pas de récupération. La dissection montre en effet que le mâle traité est incapable d'expulser de ses vésicules séminales la masse de spermatozoïdes tués par le choc réfrigérant. Il en résulte une plus ou moins grande obstruction au passage du sperme nouvellement parvenu à maturité et on assiste au phénomène exceptionnel, que des spermatozoïdes mobiles peuvent être vus dans le testicule lui-même.

Notons enfin que, comme pour le choc thermique, le choc par le froid ne modifie nullement leur comportement sexuel et que les mâles traités cherchent à s'accoupler à plusieurs reprises, sans transférer pour autant de sperme.

Wedvik (ig62) soumet des lots de mâles de la souche Canton- $S$ respectivement à des températures décroissantes : $+7^{\circ} \mathrm{C}, 4^{\circ} \mathrm{C}$ et $0^{\circ} \mathrm{C}$, pendant une demi-heure. Ces mâles sont accouplés immédiatement après. L'auteur conclut qu'il n'y a pas de différence apparente entre les mâles témoins (placés à $22^{\circ} \mathrm{C}$ ) et ceux soumis à $7^{\circ} \mathrm{C}$. Par contre il note pour les groupes de mâles soumis à $4^{\circ} \mathrm{C}$ et à $0^{\circ} \mathrm{C}$, une réduction marquée dans la fréquence des mâles fertiles, commençant dès le second jour après le traitement. Donc, pour WEDVIK les températures (égales ou inférieures à $4^{\circ} \mathrm{C}$ induisent la stérilité mâle. Mais l'action du froid ne semble pas avoir les mêmes répercussions sur l'activité sexuelle du mâle, sa fertilité et sa fécondité, selon l'âge auquel le traitement est appliqué, comme le montre KvelLAND $(1965 b)$ : une température de $0^{\circ} \mathrm{C}$ pendant 30 minutes est sans effet sur des mâles âgés de 2 heures au plus et, par contre, chez les mâles âgés de 3 jours elle affecte nettement la productivité. Aucune explication physiologique n'est avancée pour rendre compte du résultat. 


\section{DEUXIÈME PAR'TIE,}

\section{BIOLOGIE DES SPERMATOZOÏDES DANS LES VOIES GÉNTTALES FEMFILES}

\section{CHAPITRE PREMIER \\ NOMBRE DE SPERMATOZOÏDES REÇUS E'T CONSERVÉS}

\section{Nombre de spermatozoïdes transférés par copulation}

KaUfmann et Demerec (i942) donnent un nombre approchant de 4000 par femelle. (Les femelles sont disséquées immédiatement après copulation, puis le tractus génital est fixé et coloré par la méthode de Feulgen.) WigGLesworth (1965) indique un nombre similaire. Évidemment le nombre de spermatozoïdes décroît rapidement au cours des copulations successives effectuées par un mâle : il passe de 3215 à 2518 puis I 996 et enfin I 047 seulement, lors de la $4^{\mathbf{e}}$ copulation, soit seulement le $\mathrm{I} / 3$ de ce que le mâle fournissait la $\mathrm{I}^{\text {re }}$ fois (KaUfmann et Demerec, I942).

\section{Nombre de spermatozoïdes stockés et modalités de stockage}

Rappelons brièvement que les organes de mise en réserve du sperme chez la femelle de la Drosophile sont constitués tout d'abord par un organe impair, le réceptacle ventral : tube de $2 \mathrm{~mm}$ de long enroulé en spirale sur lui-même, de calibre inégal le long de son parcours (la partie proximale ayant un diamètre de $5 \mu$, la partie distale, de $30 \mu$ ), il débouche contre l'oviducte commun, au sommet de l'utérus. Sur le côté dorsal de l'utérus, s'ouvrent des organes pairs de réserve : les spermathèques, en forme de champignon, chacune ayant un diamètre de $70 \mu$ de diamètre environ. La majorité des spermatozoïdes stockés se trouvent dans le réceptacle, les spermathèques ayant un rôle secondaire chez D. melanogaster.

YANDERS (I962) établit après dissection de femelles venant de copuler, que le I ${ }^{\text {er }}$ spermatozoïde gagne le réceptacle ventral quelques minutes après l'éjaculation, c'est-à-dire 20 minutes environ après le début de l'accouplement. Le réceptacle séminal atteint son maximum de réplétion dans l'heure qui suit.

Le nombre de spermatozoïdes stockés chez une femelle correctement inséminéc paraît remarquablement bas : de l'ordre de 500 à 7oo. KAPLAN, Tinderholt et Gugler (I962) en trouvent tout au plus $65^{\circ}$ par femelle pour l'ensemble du réceptacle et des spermathèques. LEFEvRE et Jonsson (1962) estiment, à juste titre, que le nombre de spermatozoïdes transférés par un mâle dans son premier ou son second accouplement, dépasse de beaucoup la capacité des organes de stockage du sperme chez la femelle. Les évaluations des données brutes indiquent que seulement 1o à 20 p. 100 des spermatozoïdes déposés chez la femelle sont stockés. Il y a donc un " gaspillage " appréciable, de l'ordre de 80 p. roo, dans le processus de mise en réserve.

\section{Influence de divers facteurs sur le stockage}

\section{A. - Infuences raciales.}

YANDERS ( 1963 ) a montré que la vitesse relative de remplissage des organes de stockage semble différer selon les croisements inter-et intra-raciaux envisagés : 4 races géographiques ont été croisées entre elles : Oregon-R, Canton-S, Crimea et Swedish-B, ce qui a conduit Yanders à I 6 valeurs d'un 
"Index d'insémination "(I. I.). Il effectue en effet une estimation du degré de remplissage relatif du réceptacle ventral en adoptant un classement arbitraire en 5 groupes allant de o (aucun spermatozoïde) à 4 (réceptacle rempli des $3 / 4$ aux $4 / 4$ ). L'index d'insémination qui est une évaluation du succès relatif d'insémination, est le rapport de la somme des résultats bruts de chacun des 5 groupes (somme des fréquences des mouches de chaque groupe) sur la somme qui aurait été atteinte si tous les résultats avaient eu la valeur maximum 4 (autrement dit, le dénominateur représente un total théorique maximum). En exprimant ceci dans une formule on obtient donc :

$$
\text { I. I. }=\frac{n_{0} \times 0+n_{1} \times 1+n_{2} \times 2+n_{3} \times 3+n_{4} \times 4}{4\left(n_{0}+n_{1}+n_{2}+n_{3}+n_{4}\right)}
$$

Les valeurs du I. I. indiquent que la migration du sperme est proportionnellement plus lente entre certaines combinaisons de races.

YANDERS attribue ce phénomène à une action inhibitrice du tractus génital femelle sur la motilité de certaines classes de spermatozoïdes, une sorte de "réaction d'insémination " non notée jusqu'à présent chez $D$. melanogaster. Mais il ajoute avec juste raison, que cette réaction n'est pas analogue à la typique "réaction d'insémination" décrite par WHEELER (1947) car la réaction la plus forte (valeurs du I. I. les plus basses) ne devrait pas apparaître dans les accouplements intra-raciaux, comme c'est le cas observé, mais au contraire dans les croisements inter-raciaux. YANDERS (1963) hésite donc à conclure que $D$. melanogaster montre habituellement une "auto-stérilité " basée sur l'inhibition de la motilité du sperme concernant sa propre souche. Mais il pense néanmoins qu'un tel mécanisme puisse exister.

\section{$\mathrm{B}$ - Viabilité différentielle des spermatozoïdes.}

Muller et SetTles (1927) ont étudié le problème de la survie différentielle des spermatozoïdes. Ils ont montré que, chez $D$. melanogaster, la longévité des spermatozoïdes ne semblait pas dépendre de leur constitution génétique.

Par contre, à la suite de travaux effectués sous la direction de Yanders, De VRIES (Ig64) émit l'hypothèse suivante : non seulement la quantité de sperme stockée dans le réceptacle séminal de la femelle varierait dans les différents croisements (XANDERS, 1963), mais elle serait caractéristique d'une combinaison particulière mâle-femelle. D'autre part, des études du pourcentage de perte de spermatozoïdes du réceptacle ventral au-delà d'une période de temps allant de $\mathbf{r}_{5}$ à 29 jours, ont montré des différences, quand une souche de femelles était inséminée par différentes races de mâles.

DE VRIEs conclut alors, que de telles différences peuvent être dues à une viabilité différentielle de différents types de spermatozoïdes dans le tractus génital de différents types de femelles. Mais elle énet la réserve qu'aucune preuve directe n'est encore donnée. Cet auteur note que les différences physiologiques enregistrées, et notamment une viabilité différente, peuvent être en relation avec la constitution génétique des mâles.

D'autres auteurs étaient déjà parvenus à la même conclusion. NACHTSHEim (1928) notamment, en comparant les durées de vie des spermatozoïdes de différentes souches de Drosophiles, remarqua en particulier que ceux de Drosophila obscura, mutant "orange ", ont une durée de vie plus courte que les spermatozoïdes d'une souche sauvage. Il ignore si le facteur " orange " a une action ou si d'autres facteurs n'interviennent pas dans le génotype pour rendre compte de cette différence.

Remarquons que la viabilité différentielle des spermatozoïdes n'est pas admise par KaUfManN et DEMEREC (I942) à propos d'un autre problème, celui du comportement des spermatozoìdes appartenant à des génotypes différents, délivrés à des femelles effectuant des copulations multiples. Ces auteurs pensent que les différences dans la fréquence des classes de descendants obtenus, sont attribuables à une viabilité différentielle des différents types d'embryons, et des larves, et non à des différences dans la vigueur ou la mortalité, des différents types de spermatozoïdes envisagés, ce qui semblerait plus logique, à notre avis. 


\section{Chapitre II \\ UTILISATION DES SPERMATOZOÏDES}

\section{Rendement}

Il existe un gaspillage important entre le nombre de spermatozoïdes transmis et réellement mis en réserve : la majeure partie étant rejetée soit par le vagin après accouplement (WhEELER, I947), soit entraînée devant le $\mathrm{r}^{\mathrm{er}}$ œuf pondu (Kaufmann et Demerec, I942). Mais il est à noter qu'après le stockage, l'utilisation des spermatozoïdes lors de la fécondation doit être remarquablement efficace, car, succédant à un accouplement unique, la femelle de Drosophile peut produire un nombre maximum d'environ 600 descendants (DAvID, 1963). Comme la femelle n'emmagasine réellement qu'un nombre voisin de 700 spermatozoïdes, ces derniers sont utilisés avec roo p. Ioo d'efficacité. Ceci implique donc une fécondation monospermique, ce qui est vérifié par les travaux d'HILDRETH et LuccileSI $(1963)$.

\section{Mécanismes d'utilisation}

LEFEVRE et Jonsson ( $1962, c)$, qui se sont livrés à une étude détaillée des spermatozoïdes dans les voies génitales femelles, avouent que le mécanisme par lequel les organes de stockage libèrent les spermatozoïdes un par un, n'est pas clair. A partir de leurs observations sur le vivant, ces auteurs suggèrent que les spermatozoïdes sont en continuel état de circulation dans le réceptacle, de sorte qu'à n'importe quel moment, plusieurs de ceux-ci s'avancent vers "l'utérus " tandis que d'autres sont en mouvement dans la direction opposée (celle de l'extrémité distale aveugle du réceptacle séminal).

La fécondation est alors un phénomène soumis au hasard de la présence ou non d'un œuf atteignant " l'utérus " au moment ou un spermatozoïde sort du réceptacle. Par contre, pour GARCIABELLIDO (1964), le réceptacle ventral serait normalement fermé. Il invoque un mécanisme d'ouver. ture, il pense en effet que la sécrétion des paragonia mâles agirait peut-être comme stimulus pour l'ouverture du réceptacle séminal chez la femelle. Il estime qu'une telle ouverture est indispensable, à la fois pour assurer l'admission des spermatozoïdes, ainsi que leur sortie, afin de féconder les ovocytes. Garcia-Bellido parvient à cette hypothèse en se référant à un travail antérieur de Meyer (I956). Ce travail en effet laisse supposer qu'il faut peut-être un nombre minimum de spermatozoïdes et de sécrétion des paragonia dans l'éjaculat pour assurer une fécondation normale.

En ce qui concerne l'épuisement des spermatozoïdes, Kaufmann et Denerec (I942) pensent qu'un grand nombre de ceux-ci sont gaspillés lors de la ponte du $\mathrm{I}^{\mathrm{er}}$ œuf, et que la fécondité plus faible des œufs pondus ensuite, est imputable à ce gaspillage initial.

La fertilité de la femelle étant fonction du nombre de spermatozoïdes disponibles, la femelle commence à pondre des œufs stériles à partir du Io jour si elle n'est pas à nouveau soumise à un $2^{\mathrm{e}}$ accouplement. Ces auteurs indiquent que la ponte d'œufs non fécondés se fait à partir du $8^{\mathrm{e}}$ jour quand on utilise un mâle qui est à sa $2^{\mathrm{e}}$ copulation, et dès le $7^{\mathrm{e}}$ jour pour un mâle à sa $3^{\mathrm{e}}$ copulation. Ceci est curieux, car au cours d'une $2^{\mathrm{e}}$ ou $3^{\mathrm{e}}$ copulation, le mâle fournit encore 2000 à 2500 spermatozoïdes. On comprend mal que la fertilité de la femelle diminue dans ces circonstances puisque, de toute façon, ses organes n'emmagasinent que de 5 à 700 spermatozoïdes.

\section{Infuence de l'âge de la femelle}

A la suite des travaux d'Hadorn et Zeller (I943), de David et Croissant (1956), ces auteurs ont attiré l'attention sur le fait que le stockage des gamètes diminue en fonction du vieillissement des femelles; la fécondation des œufs devient alors mauvaise dès que le nombre de spermatozoïdes présents n'est pas élevé. Il y a alors ponte d'œufs stériles et d'œufs fécondés en même temps. 


\section{Polyspermie et Monospermie dans l'auf de Drosophile}

\section{A - La Polyspermie.}

Huettner (1927) examinant 300 œufs de D. melanogaster, trouva seulement 9 œufs monospermiques, par contre, 29I étaient prétendus polyspermiques, dont quelques-uns avec même plus de 3o spermatozoïdes. A cette époque la polyspermie était considérée comme un phénomène normal chez cet Insecte. Kaufmann et Demerec (I942) estimaient, en comparant le nombre de spermatozoïdes délivrés lors de la copulation avec le nombre total d'œufs fécondés, que la femelle utilise en moyenne environ 20 à 30 spermatozoïdes par œuf fécondé. Ces auteurs admettaient donc également l'existence de spermatozoïdes surnuméraires lors de la fécondation. Sonnenblick (I950) déclare aussi que la polyspermie est la règle générale chez Drosophila. Counce (1959) confirme les résultats d'HuetTNer (1924, 1927) et les étend à 8 nouvelles espèces de Drosophiles et trouve une moyenne de 5 à 6 spermatozoïdes par œuf chez D. melanogaster et $5^{\circ}$ à roo dans les œufs de D. virilis.

\section{B - La Monospermie.}

Il faut attendre les publications successives d'HildreTh et Lucchesi (I961, I962, I963a, I $963 b$ ) pour qu'apparaisse la contradiction de l'opinion précédente. Ces deux auteurs apportent en effet la preuve de l'existence régulière de la monospermie, mais aussi, la raison pour laquelle les partisans de la polyspermie observaient un nombre si élevé de spermatozoïdes dans les coupes d'oufs examinés. Ils montrent $\left(\mathrm{I}_{96} 6_{3} b\right)$ que la technique de coloration est responsable des différences dans les degrés de polyspermie observés par les différents auteurs : en effet l'hématoxyline ferrique n'est pas une coloration spécifique de l'ADN et peut aller jusqu'à colorer le flagelle du spermatozoïde.

Le spermatozoïde de Drosophile a une longueur approximative de I,75 mm (Cooper, I96o; Yanders et Perras, I960). Il est environ 3 fois plus long que l'œuf et une grande partie du flagelle pénètre dans l'œuf au moment de la fécondation. Il en résulte donc que des fragments du flagelle et d'autres éléments cellulaires ne portant pas d'ADN, colorés par l'hématoxyline dans des sections d'œufs, peuvent être pris par erreur pour des têtes de spermatozoïdes.

HiLdRETH et LuCCHESI ( $196 \mathrm{I}$ ) ont donc utilisé un procédé de montage d'œufs in toto et la coloration de Feulgen (spécifique, elle, de l'ADN) selon la technique de VON Borstel et LindSLEY (1959). Ils constatèrent qu'aucun cas de polyspermie n'était observé dans 87 œufs fécondés de $D$. virilis et que parmi 165 œufs fécondés de D.m. 6 seulement étaient dispermiques (HrLdRETH et Lucchesi, $(1963 b)$. Ces mêmes auteurs ont effectué une série d'autoradiographies dans laquelle ils combinent le marquage à la thymidine tritiée et la coloration de Feulgen sur les spermatozoïdes. Cette technique connfirme la validité des résultats obtenus après la coloration de Feulgen.

En conclusion, ces auteurs affirment que chez la Drosophile la monospermie est la règle générale et non la polyspermie, la dispermie apparaît avec une fréquence faible $(2,2 \mathrm{p}$. Ioo) et de façon occasionnelle. Toutefois, chez le mutant " deep-orange » HiLdRETH et Lucchesi ( ${ }^{6} 6_{3} a$ ) trouvent que la fréquence de la dispermie est légèrement plus forte (9,4 p. Ioo).

Counce (1963) modifie son opinion précédente et conclut que le nombre des spermatozoïdes surnuméraires par œuf est probablement bas. Il se rallie donc, en fait, aussi à la thèse de la monospermie.

\section{Problème du mélange des spermatozoïdes au cours de fécondations successives}

On peut grouper en 3 catégories les positions adoptées par les différents auteurs à l'égard de cette question étudiée depuis 1920 et reprise avec des interprétations chaque fois différentes, remettant toujours en question le problème de savoir si des femelles inséminées plusieurs fois dans un intervalle de temps assez court, présentent ou non, une utilisation au hasard des spermatozoïdes.

A - Première hypothèse formulée : celle du mélange au hasard des spermatozoïdes (NoNIDEz, i920).

Utilisant successivement des mâles sauvages et des mâles Bar pour féconder des femelles de type sauvage, il obtient la coexistence des 2 types de descendance. Il précise même l'ordre d'utilisa- 
tion des spermatozoïdes à partir des organes de stockage : ce sont ceux qui sont dans le réceptacle ventral qui sont utilisés en premier, ceux des spermathèques en dernier.

Cette théorie du mélange des spermatozoïdes est approuvée également par LoBAshov (I939). EhrLich (I959) conclut que le type qui émerge à la $F_{1}$, correspond au mâle qui a donné le plus de spermatozoïdes, mais que ces spermatozoïdes sont utilisés parfaitement au hasard.

\section{$\mathrm{B}$ - Deuxième hypothèse : stratification ou superposition des spermes.}

NAChTSheim (1927) a utilisé un intervalle de temps de 6 à 8 jours entre la Ire et la $2^{\mathbf{e}}$ copulation. Il observe que, aussitôt la $2^{\mathrm{e}}$ copulation accomplie, la production des descendants du ${ }^{\mathrm{er}}$ mâle cesse soudainement et qu'apparaissent alors les descendants du $2^{\mathrm{e}}$ mâle. Puis après un certain temps, surviennent à nouveau des descendants du ${ }_{\mathrm{I}}^{\mathrm{er}}$ mâle, pendant que le nombre de descendants du $2^{\mathrm{e}}$ mâle baisse de plus en plus.

NACHTSHEIM conclut : après la $2^{\mathrm{e}}$ copulation il n'y a pas mélange des 2 sortes de sperme dans le réceptacle ventral, mais le sperme le plus récent sera "superposé "sur le sperme du ${ }^{\text {er }}$ mâle et utilisé en premier. Ce n'est seulement que lorsque le sperme du $2^{\mathbf{e}}$ mâle arrive à être presque totalement utilisé, que survient à nouveau l'emploi du sperme le plus ancien.

Une perspective intéressante formulée par cet auteur est de considérer la méthode des doubles ou multiples copulations comme une voie utile pour conserver des spermatozoïdes âgés et étudier ensuite l'influence de l'âge sur ces derniers. C'est certainement par cette méthode que MULLER (I940) a noté que le sperme est encore fonctionnel après 30 jours dans la femelle.

\section{$\mathrm{C}$ - Troisième hypothèse : Déplacement des spermatozoïdes.}

Tout d'abord, Dubinin (I928), puis Kaufmann et Demerec (1942) parviennent à la conclusion que les spermatozoïdes nouvellement déposés éliminent complètement le type préalablement déposé.

Meyer et Meyer (196I) expérimentent sur 37 femelles doublement inséminées, dans un intervalle de 4 à 5 jours recueillent à la suite de la $2^{\mathrm{e}}$ fécondation seulement 2, I p. Ioo d'individus appartenant au i er type de mâle (soit i 1o/5 I35).

Plus récemment, Lefevre et Jonsson ( $1962 c$ ) ont repris des expériences de doubles copulations. Ces deux derniers auteurs parviennent aux conclusions suivantes :

a) Les femelles accouplées une seule fois produisent une descendance équivalente en nombre à celle obtenue chez des femelles accouplées deux fois de suite. (Ce qui montre que les organes de stockage des spermatozoïdes chez la femelle ne sont pas extensibles et qu'il n'y a pas accumulation d'une quantité double de spermatozoïdes pour autant.)

b) Après réaccouplement, la progéniture donnéc par le ${ }^{\mathrm{er}}$ mâle est toujours moindre que lorsque la femelle n'est fécondée qu'une seule fois.

Pour comprendre l'hypothèse du déplacement des spermatozoides rappelons que LEFEvre et JoNSSON furent les premiers à montrer la répartition réelle de ceux-ci dans le réceptacle ventral : les têtes des spermatozoïdes ne convergent pas toutes vers l'extrémité distale aveugle du réceptacle, mais elle sont identifiées comme étant tournées soit vers l'intérieur soit vers l'intérieur, et ceci, sur toute la longueur du réceptacle. Ainsi une circulation de spermatozoïdes paraît exister à ce niveau de telle sorte que plusieurs spermatozoïdes entrent dans le réceptacle, tandis que d'autres en sortent dans le même instant. En cas de réaccouplement, la circulation provoque la sortie de spermatozoïdes déposés par le premier mâle. Ils sont alors mélangés dans l'utérus parmi la grande quantité de spermatozoïdes déposés par le second mâle. La probabilité d'une "rentrée » des premiers spermatozoïdes dans le réceptacle est alors fort réduite, et la majorité des spermatozoïdes qui y pénètrent alors est constituée par ceux du $2^{\mathrm{e}}$ mâle.

Ces auteurs prétendent donc qu'un réaccouplement n'a pas pour résultat de former une sorte de stratification dans le réceptacle ou les spermathèques, mais plutôt de déplacer une plus ou moins grande proportion de spermatozoïdes déjà présents. 
En fait, il y a à la fois mélange et déplacement des spermatozoïdes. Il faut préciser d'ailleurs que le degré de déplacement du ${ }^{\text {er }}$ sperme par le second n'est pas uniforme et qu'il est lié à de nombreux facteurs dont le plus important paraît être l'activité de ponte de la femelle : selon que celle-ci pondra immédiatement ou non après son $2^{\mathrm{e}}$ accouplement, il n'y aura pas de déplacement de sperme observé, ou au contraire un déplacement maximum (LeFEvre et Jonsson (I962 c).

Une récente publication de GugLER, KAPLAN et KIDD ( $\left.{ }^{6} 6_{5}\right)$ vient renforcer l'hypothèse du déplacement des spermatozoïdes : des femelles âgées de $24 \mathrm{~h}$ étaient d'abord accouplées à des mâles vierges du même âge, de la souche Canton-S, puis immédiatement après, présentées à des mâles de la même souche, mais chez lesquels les gamètes avaient été préalablement marqués avec de la désoxycytidine tritiée. Des préparations et des autoradiographies concernant réceptacle ventral et spermathèques étaient faites. Ces auteurs concluent que, dans tous les cas, plus de la moitié des spermatozoïdes des spermathèques et du réceptacle proviennent du second accouplement (spermatozoïdes marqués). Les auteurs précisant que les spermatozoïdes utilisés par les mâles ainsi traités, lors de leur $\mathrm{I}^{\mathrm{er}}$ accouplement, contenaient $90 \mathrm{p}$. roo de faisceaux de spermatozoïdes marqués, ceci semble être une garantie suffisante pour formuler leur conclusion.

Ces expériences donnent également une idée du temps qu'exige ce déplacement, puisque ces auteurs observent que, déjà au bout de 20 minutes, les gamètes du $2^{\mathbf{e}}$ accouplement peuvent remplacer ceux résultant du $\mathrm{I}^{\mathrm{er}}$.

\section{D - Influence de la vitalité des spermatozoïdes.}

I.EFEVRE et JONSSON (I $962 c$ ) notent que le sperme provenant de mâles de type sauvage est en moyenne plus efficace à déplacer, le sperme de types mutants tels par exemple (vermilion, forked $3 n$... carnation) plutôt que l'inverse.

Ces auteurs utilisant des mâles génétiquement stériles ( $\mathrm{X} \mathrm{O}$ ) (montrant à peu près invariablement une spermiogenèse incomplète et en conséquence produisant des spermatozoïdes immobiles), n'ont pas obtenu de déplacement du sperme viable par le sperme non fonctionnel de ceux-ci (ce qui constitue une preuve supplémentaire pour l'hypothèse du déplacement).

Par ailleurs, ces auteurs réaccouplent des femelles avec des mâles irradiés et observent que la fertilité est réduite de $60 \mathrm{p}$. Ioo. Mais, bien que les radiations produisent un niveau élevé de létaux dominants, ils prétendent que la motilité du sperme n'est pas affectée (contrairement à l'opinion de YandERs, 1964). En conséquence, le sperme normal a dû être largement remplacé par le sperme irradié défectif.

\section{Résorption des spermatozoüdes chez la femelle}

\section{A - Influence de la mutrition.}

GuYÉnot (I9I3) a constitué des couples de mouches dont les larves avaient été nourries sur milieu fermenté (levure). Les adultes furent placés sur milieu carencé (pomme de terre), une quarantaine d'œufs seulement sont fécondés, viennent ensuite des œufs avortés qui brunissent et enfin des œufs vierges. Bien que les mâles utilisés soient génitalement mûrs, les spermatozoïdes ne sont plus susceptibles de réaliser la fécondation au bout de très peu de temps. GuYÉnot conclut qu'il semble que les spermatozoïdes subissent des altérations dans le réceptacle ventral des femelles mal nourries (avortement des œufs), suivies de résorption définitive (ponte d'œufs vierges).

Il souligne enfin que ce réceptacle ventral ne saurait en conséquence, être considéré comme un simple réservoir et que la résorption des spermatozoïdes est sous l'influence directe de mauvaises conditions de nutrition de la femelle. Peut-être aussi l'âge de la femelle agit-il également (HADORN et ZELLER, 1943) ainsi que nous l'avons mentionné plus haut.

\section{$\mathrm{B}$ - Influence du froid.}

Plusieurs auteurs sont parvenus à réduire la fertilité des femelles fécondées en les soumettant à un traitement par le froid (Novitski et Rush, I948), Scossirolli (1954), Frydenberg et Sick 
(I960). Scossirolli (1954) indique une durée optimum de $5^{\circ}$ minutes à $-5^{\circ} \mathrm{C}$ comme traitement afin d'obtenir la stérilisation des femelles préalablement inséminées. Mais il précise que la durée d'exposition semble varier avec la lignée utilisée.

Frydenberg et Sick (I960) ont observé que, en réponse à un traitement de 45 minutes par le froid (Drosophiles placées dans un container immergé dans de la glace pilée) les femelles fécondées, de différentes souches, se comportent très différemment :

$\mathrm{I}^{\mathrm{O}}$ certaines souches sont très résistantes au froid, la fécondité et la fertilité n'étant pas modifiées notablement,

$\mathbf{2}^{\mathbf{0}}$ d'autres sont très sensibles : la fécondité et la fertilité deviennent pratiquement nulles,

$3^{\circ}$ au-delà d'une période d'un an ou plus, en les soumettant de nouveau à ce traitement, le degré de résistance d'une souche peut subir des changements spontanés. Dans la plupart des cas ils notent que les souches deviennent plus sensibles avec le temps. Mais l'inverse peut également se produire. Ces auteurs pensent que le degré de résistance trouvé dans une souche est largement imputable aux spermatozoïdes de cette souche plutôt qu'à la femelle : on obtient des résultats identiques quand les femelles de différentes souches sont fécondées par la même espèce de mâles.

Par contre, notons que des femelles fécondées, stockées à des températures moins basses $\left(+10^{\circ} \mathrm{C}\right.$ pendant ${ }_{5} 5$ jours) subissent un ajournement du développement normal des ovaires et une réduction de la perte de sperme, auparavant associée avec l'oviposition (MYszewski et YandERS, 1963, ceci dans le but de tester la survie différentielle des spermatozoïdes).

\title{
ChAPITRE, III
}

\author{
INFLUENCE DE LA FÉCONDATION \\ SUR I,A PHYSIOLOGIE SEXUELLE DE LA FEMEL $L_{1} E_{1}$
}

\section{A - Comportement sexuel : état de réceptivité ou non}

Reprenant sur D. melanogaster les travaux que Sмiтh (1956) effectua sur D. subobscura, MAN. NING $(\operatorname{Ig} 62 a, b)$ détermina le temps minimum au bout duquel les femelles se réaccouplent. Cela est important pour effectuer des expériences de fécondations hétérospermiques. Il enregistre en effet, à la suite d'un premier accouplement, une période de 4 jours pendant laquelle les femelles demeurent totalement réfractaires à l'accouplement. Puis la réceptivité des femelles reprend à nouveau pour atteindre son maximum au $9^{\mathrm{e}}$ jour après le $\mathrm{I}^{\mathrm{er}}$ accouplement. Par dissection du réceptacle séminal des femelles et estimation du degré de remplissage de ce dernier, d'après une échelle arbitraire, il parvient néanmoins à montrer qu'il existe une relation entre le degré de remplissage du réceptacle et l'état de réceptivité : il ressort de l'étude statistique que les femelles réceptives sont celles qui ont épuisé leur réserve de sperme, tandis que celles qui demeurent réfractaires à l'accouplement sont celles qui possèdent encore des réserves de spermatozoïdes. Ce qui amène Manning à supposer l'existence d'une substance chimique contenue dans le sperme et agissant comme inhibiteur chimique de la réceptivité. Lorsque la concentration de cette substance tombe au-dessous d'un certain seuil - au moment où le stock de spermatozoïdes est à peu près entièrement épuisé - l'état de réceptivité est alors rétabli.

ManNing (Ig62 a) pense que ce "facteur chimique n serait produit soit par le sperme lui-même, soit par interaction avec les tissus de la femelle. Mais une telle substance n'a pas encore été isolée par voie chimique. Dans un second article, Manning ( $1962 b)$ analyse de manière plus précise la nature des mécanismes mis en jeu à la suite de la fertilisation. Tout d'abord il invoque l'action d'une hormone élaborée par les corpora allata, ou bien celle d'un mécanisme neuro-sécréteur émanant du cerveau, qui tendrait à augmenter la réceptivité sexuelle, nulle d'abord à l'émergence, et qui croîtrait rapidement entre le $\mathrm{I}^{\mathrm{er}}$ et le $2^{\mathrm{e}}$ jour pour atteindre son maximum à 3 ou 4 jours. Après quoi elle 
baisserait lentement. Puis, lors de l'accouplement les stimuli reçus par la région génitale auraient pour effet d'inhiber nerveusement le mécanisme de la réceptivité. Mais ceci n'aurait qu'une action fugace. Manning prétend qu'il s'y superpose une action plus durable due à la libération dans le sperme d'une substance chimique qui induirait, pour une longue période, l'inhibition du mécanisme de réceptivité. Il ne peut du reste pas préciser par laquelle des 2 voies elle s'exerce : elle peut agir sur le cerveau ou les corpora allata directement, soit influencer le contrôle du premier sur le second.

Mais ManNing prend soin de conclure que ces déductions sont faites d'après la connaissance de systèmes trouvés chez d'autres Insectes, bien que fondamentalement similaires, les Insectes varient beaucoup d'un groupe à l'autre dans le mode de relation : croissance des ovaires et réceptivité sexuelle.

\section{B - Fécondité de la femelle en rapport avec la fertilisation}

DAvid $\left(196_{3}\right)$ a montré que selon qu'elles sont fécondées ou non, des femelles hétérozygotes peuvent se trouver dans 2 états physiologiques distincts : par le nombre d'œufs pondus d'abord et ensuite par la taille de ceux-ci.

Il a défini : "l'état activé " où les femelles fécondées pondent chaque jour une centaine d'œufs d'une longueur moyenne de $0,53 \mathrm{~mm}$, et l'état " non activé " caractérisant les femelles vierges ou les femmes privées de mâles depuis assez longtemps. Le nombre d'œufs pondus, est seulement de l'ordre de la moitié (une cinquantaine) et leur taille, par contre, augmente légèrement $(0,54 \mathrm{~mm})$. Il montre que ces deux états sont parfaitement réversibles : on passe facilement de l'un à l'autre en retirant ou en ajoutant des mâles. Il conclut que la présence des spermatozoïdes dans les voies génitales femelles joue un rôle essentiel dans le déclenchement et surtout dans le maintien de l'état activé.

Plus récemment, Garcia-Bellido (I964) montre le rôle qu'exerceraient, non plus les spermatozoïdes sur la fécondité chez la femelle, mais les glandes accessoires mâles ou paragonia. Il implante des vésicules séminales à des femelles vierges, la fécondité ${ }^{(1)}$ demeure semblable à celle de la série de contrôle ; par contre, les femelles hôtes vierges subissant l'implantation de paragonia, montrent une élévation durable de la fécondité comme ce fut le cas pour les femelles fécondées $\left(2^{\mathrm{e}}\right.$ type de contrôle). Cet auteur est parvenu également à injecter le liquide des paragonia et ceci aurait rehaussé de façon significative la fécondité existante. Garcia-BEllido conclut, de façon peut-être trop formelle, que la sécrétion des paragonia contient la matière stimulante de la fécondité. Mais il précise que rien n'est connu sur la nature chimique de cette substance. Il fait alors appel au "peptide sexuel " trouvé par CHEN et DiEM, en 196I, dans les paragonia comme cause possible du facteur stimulant.

Tout récemment LEahy (ig66) confirme les résultats de Garcia-Bellido : la transplantation de paragonia mâles est suivie chez des femelles vierges d'une augmentation spectaculaire de la ponte des œufs, alors que celle des testicules est sans effet.

La fécondité d'une femelle inséminée, après être passée par un maximum qui dure quelques jours, décroît régulièrement avec la consommation des spermatozoïdes, jusqu'à ce qu'elle corresponde à celle des femelles vierges. (David et CrorsSant, I956 ; David, 1963). Que survienne une seconde copulation, la fécondité remonte très vite de nouveau. Il semblerait alors que la fécondité dépendrait de l'état de réplétion du réceptacle séminal (pression de l'éjaculat, ou bien stimuli occasionnés par Je mouvement des spermatozoïdes sur les parois du réceptacle). C'est l'hypothèse à laquelle parvient David (1963). Par contre, Garcia-Bellido (1964) semble imputer l'augmentation de la fécondité à une action chimique : celle des paragonia. Il procéda à cet effet à des expériences de copulation avec des mâles normaux, interrompues à des temps définis ( $4^{\mathrm{e}}$ et $8^{\mathrm{e}}$ minutes) afin de recueillir différentes quantités d'éjaculat. Après une durée de copulation de 4 minutes, aucun spermatozoïde n'est transféré, et l'auteur note que la fécondité reste aussi basse que chez les femelles de contrôle. Lorsque la

(1) La féconditê che $z$ la femelle est entendue comme le nombre d'œufs pondus par jour. La fertilité étant le pourcentage d'éclosion des oufs. 
copulation est interrompue à la $8^{\mathrm{e}}$ minute, l'auteur enregistre une prompte élévation de la fécondité. Le nombre d'œufs pondus s'abaisse cependant plus tôt, et - fait curieux - n'est pas en corrélation avec la réserve de spermatozoïdes.

Garcia-BELLido considère donc comme invraisemblable que l'état de réplétion du réceptacle agisse comme excitant, ou que les spermatozoïdes comme tels, stimulent la fécondité.

S'il attribue aux paragonia, ainsi que nous l'avons vu plus haut, le rôle de stimulus chimique, il faut néanmoins citer l'observation de DAvID ( ${ }^{6} 6_{3}$ ) qui effectua des expériences de copulation avec des mâles génétiquement stériles (dépourvus de chromosomes $\mathrm{Y}$ ). L'état " activé " des femelles est maintenu de façon très fugace, alors que ces mâles présentent pourtant des paragonia bien développés (l'éjaculat est seulement constitué par les sécrétions de ces glandes annexes). Des accouplements fréquents sont alors nécessaires pour maintenir l'état d'activation, ce qui prouverait que les paragonia ne seraient pas le seul facteur en cause, mais on peut aussi penser que l'absence de $\mathrm{Y}$ peut modifier la qualité des sécrétions. Il est donc difficile de prendre position sur ce problème et il faut attendre des expériences plus décisives à ce sujet.

\section{C - Corpus allatum et fécondation}

Chez la femelle vierge le volume du corpus allatum reste assez faible (DOANE, I961) et son activité sécrétrice est probablement réduite.

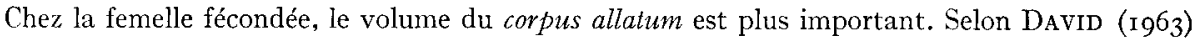
les modifications qui surviennent quand la femelle passe de l'état inactivé à l'état activé s'expliqueraient comme suit : des stimuli d'origine nerveuse modifieraient l'activité sécrétrice du corpus allatum, à son tour l'activité générale du métabolisme de synthèse se trouverait affectée, ce qui retentirait finalement sur la quantité d'œufs produits.

On sait en effet que les corpora allata exercent leur action physiologique par des effets métaboliques (mobilisation des substances de réserves comme le prouvent les expériences d'allatectomie aboutissant généralement à l'hypertrophie des cellules adipeuses).

Mais il existe également un mécanisme de rétro-contrôle, à savoir que l'activité ovarienne affecte la fonction des corpora allata, en exerçant à leur égard une activité modératrice. DoANE (Ig6I) signale que chez le mutant adpladp, l'hormone ovarienne est déficiente, et il montre que le corpus allatum de telles femelles s'hypertrophie typiquement après accouplement, mais, que le corpus allatum demeure d'une taille raisonnable, si on implante à de telles femelles des ovaires de type sauvage.

\section{CONCLUSIONS}

\section{A - Bilan des connaissances sur les points traités}

- Le déroulement de la spermatogenèse chez le mâle de Drosophile requiert une huitaine de jours. Elle demande 24 heures de plus lorsqu'il s'agit de testicules immatures.

- Par ailleurs, il existe un retard de 24 heures dans la spermatogenèse chez les mâles ayant subi une irradiation de $\mathbf{I}$ ooo $\mathrm{r}_{4} 8$ heures après l'émergence par rapport à celle qui se déroule chez les mâles témoins. Ce retard serait induit par les rayons $\mathrm{X}$.

- Le nombre de spermatozoïdes émis au cours d'une ${ }^{\text {re }}$ copulation est de l'ordre de 4 ooo (pour une souche vigoureuse).

- La fécondité mâle (nombre de descendants engendrés) augmente avec l'âge : à partir du moment où l'imago est complètement mûr $(24 \mathrm{~h})$ jusqu'à ce que'il ait atteint $72 \mathrm{~h}$. Par la suite, la fécondité décroît régulièrement jusqu'au $3^{0^{\mathrm{e}}}$ jour. Il s'ensuit alors une période de stérilité dont on ignore encore la cause précise. 
- Le nombre de descendants que peut fournir un mâle au cours de sa période fertile varie selon les auteurs : certains donnent une moyenne de 3980 mouches par mâle, d'autres, correspondant à des travaux plus anciens : de Io à 14000 mouches. Ce nombre dépend de la souche utilisée et de la durée de vie du mâle, variable d'un mâle à l'autre.

- On ignore complètement le nombre total de spermatozoïdes produits par un mâle, et les chiffres avancés ne correspondent qu'à des considérations théoriques.

- L'activité spermatogénétique est un problème non encore bien résolu. On pense qu'elle se fait à vitesse constante, mais l'on se trouve devant diverses modalités possibles. Pour certains, le taux d'utilisation serait indépendant du taux de production. Par contre, pour d'autres auteurs ces 2 phénomènes seraient liés. De ce fait, le problème du stockage ou de la résorption des spermatozoïdes chez le mâle, n'est pas résolu.

- Un mâle de 3 jours peut féconder efficacement en moyenne une dizaine de femelles dans les 24 heures.

-_ La stérilité naturelle du mâle, à la suite d'une série d'accouplements durant une période de 3 à $4 \mathrm{~h}$, provient de l'épuisement en sécrétion des glandes accessoires ou paragonia.

- La sécrétion des paragonia assume un rôle essentiel dans le transfert des spermatozoïdes, tant dans les voies mâles que dans les voies femelles.

- La durée d'accouplement est fonction du génotype de la lignée utilisée, et pourrait constituer, d'après certains auteurs, une barrière génétique dans le maintien du polyınorphisme chromosomique dans les populations naturelles.

- Ia fertilité après insémination est nettement abaissée quand les mâles sont irradiés avant accouplement à des doses de $4000 \mathrm{r}$ ou plus.

- Il semble que la motilité du spermatozoïde soit affectée par le rayonnement $\mathrm{X}$ aux doses habituellement employées en génétique

- La température, à partir de $30^{\circ} \mathrm{C}$, a un effet stérilisant chez le mâle à condition d'agir pendant une semaine au moins.

- Les températures égales ou inférieures à $4^{\circ} \mathrm{C}$ induisent la stérilité mâle de façon régulière.

- Le nombre de spermatozoïdes stockés dans le réceptacle ventral et les spermathèques de la femelle est relativement petit ( 500 à 700 ), ce qui représente seulement $\mathbf{5} 5$ à $20 \mathrm{p}$. Ioo du nombre de spermatozoïdes initialement transférés. Il y a donc un gaspillage important durant le stockage.

- La migration du sperme dans les organes de stockage de la femelle est influencée par les différences raciales. Selon les croisements inter-et intra-raciaux envisagés, on assiste à des différences de degré de remplissage mises en relief par des valeurs différentes de l'Index d'Insémination, qui a été défini par YANDERS.

- Le mécanisme de libération des spermatozoïdes du réceptacle et des spermathèques pour féconder les œufs n'est pas clair (LEFEVRE et JonsSON, 1962,c; YANDERs, 1963). Ces derniers suggèrent que le réceptacle demeure ouvert en permanence et qu'une circulation continuelle des spermatozoïdes a lieu dans les 2 sens le long du réceptacle. Par contre, Garcia-Bellido (ig64) pense que c'est la sécrétion des Paragonia qui constituerait le stimulus de l'ouverture du réceptacle séminal.

Le problème est complexe et non encore résolu.

Précisons pour ce qui est des spermathèques, LEFÈvre et Jonsson ne semblent pas avoir mis leur rôle autant en évidence que pour le réceptacle. Ils ne nient pas qu'une circulation semblable à celle qui règne dans le réceptacle ne soit pas impossible, mais qu'elle existerait à un beaucoup plus faible degré.

- Après avoir eu des adeptes nombreux, la thèse de la polyspermie chez la Drosophile a maintenant cédé la place à celle de la monospermie - sauf rares exceptions.

- En ce qui concerne les résultats des expériences de doubles fécondations accomplies par les mâles génétiquement différents, l'hypothèse qui semble être sans doute la plus exacte, est celle du 
déplacement des spermatozoïdes du ${ }_{\mathrm{I}}^{\text {er }}$ type de mâle par ceux du second, avec la possibilité néanmoins qu'une fraction des premiers se trouve plus ou moins mélangée aux seconds, selon l'activité de ponte de la femelle. En tout cas, l'hypothèse de la stratification est actuellement abandonnée.

- La provision de spermatozoïdes de la femelle est sujette à résorption sous l'influence de divers facteurs, tels que le vieillissement de la femelle, une malnutrition de celle-ci, ou d'agents tels que le froid.

- En soumettant les femelles à des températures inférieures à $\circ^{\circ} \mathrm{C}$ la fécondité et la fertilité sont fortement affectées selon les souches utilisées.

- L'état de réceptivité, élevé, chez les femelles vierges, tendrait à être inhibé à la suite d'un accouplement, par voie nerveuse d'abord, puis par une substance chimique contenue dans le sperme, mais celle-ci n'est qu'hypothétique.

- La fécondation retentit sur le rythme de la ponte chez la femelle, ainsi que sur la taille des œufs pondus. Les avis des auteurs sont partagés en ce qui concerne le mécanisme du maintien de la fécondité. Le stimulus peut être : soit l'état de réplétion du réceptacle séminal, soit une substance chimique contenue dans les paragonia et l'éjaculat par voie de conséquence.

Enfin, l'action de nombreux facteurs expérimentaux sur les spermatozoïdes, tant chez le mâle que chez la femelle, est mal connue.

\section{B - Perspectives sur d'autres problèmes qui restent à élucider}

Plusieurs problèmes concernant la reproduction des Insectes et de la Drosophile en particulier, ne sont pas encore résolus. On insistera surtout sur quelques-uns que nous passerons brièvement en revue en nous appuyant sur la conclusion de DE VRIEs ( $\left.19^{64}\right)$ :

I. On ignore complètement s'il existe ou non un mécanisme sélectif opérant vis-à-vis des gamètes mâles stockés chez la femelle : si la sélection gamétique existait, elle représenterait une force évolutive non négligeable, et un tel phénomène mériterait d'être plus complètement recherché.

2. On ne sait pas encore actuellement si les gènes sont actifs ou non dans les spermatozoïdes. Pendant longtemps on a admis que l'ADN du spermatozoïde était entièrement inerte et que l'aptitude fonctionnelle de ce dernier était indépendante de son contenu génétique (Muller et Setrles, 1927). Toutefois certains gènes dans les spermatozoïdes de Drosophile sont connus pour fonctionner immédiatement après leur introduction dans l'œuf (Glass et Plaine, 1950; Counce, 1956); ou bien pour exercer leur action spécifique à différents moments du développement (HADORN, I958). Cependant DE VRIEs (I964) précise qu'il n'y a pas de possibilité de démontrer actuellement si les gènes sont actifs ou non dans le spermatozoïde.

3. DE VRIES (1964) soulève par ailleurs un problème de dynamique cellulaire : les spermatozoïdes sont observés in vitro comme animés de mouvements d'ondulation, ils ne montrent aucun mouvement de propulsion vers une direction donnée. On comprend alors mal, comment les spermatotozoïdes se dégagent eux-mêmes de l'enchevêtrement dans lequel ils se trouvent lorsqu'ils sont dans l'utérus de la femelle, pour gagner ses organes de mise en réserve, sans invoquer une chimiotaxie. DE VRIES pense qu'interviennent à la fois l'activité propre du spermatozoïde, ainsi que les contractions musculaires du tractus génital de la femelle, ainsi que l'a démontré DAVEY (I958) chez la femelle d'un Hémiptère du genre Rhodnius.

Plusieurs auteurs ont été amenés à suggérer que les spermatozoïdes suivraient un gradient chimique (chimiotaxie) : WeIDNer (1934) pour Bombyx mori, KerR et al. (1962) pour les Abeilles. Mais Carayon ( 1964 ) à propos des Hémiptères Lygaeidés, avoue en parlant "d'effet chimiotactique ", que l'on ignore complètement la substance mise en cause.

DAvey (1965) indique en effet qu'il faut être très prudent avant d'invoquer la chimiotaxie, car d'après lui, seuls les gamètes mâles de certaines Fougères, relèveraient du phénomène de chimio- 
taxie. Précisons que celui-ci serait peu répandu dans le règne animal : il concernerait les substances émises par le micropyle de l'cuf des Poissons, à notre seule connaissance.

Reçu pour publication en juin 1966.

\section{REMERCIEMENTS}

Je tiens à exprimer mes vifs remerciements à M. Jean DAvid, de la Faculté des Sciences de Lyon, qui m'a suggéré d'effectuer cette mise au point et a bien voulu accepter d'en relire le manuscrit.

J'exprime ma gratitude à M. Thibault, directeur de la Station de Physiologie animale de l'I.N.R.A. pour l'intérêt qu'il a manifesté à ce travail, les suggestions utiles et bienveillantes qu'il m'a adressées et pour avoir permis sa parution dans cette Revue.

\section{SUMMARY}

ASPECT OF REPRODUCTIVE HIOLOGY IN " DROSOPIILA MELANOGASTER "

The literature that has been published for 50 years on the reproductive biology and sperm physiology of the male Drosophila is analyzed and summarized here. A distinction is attempted between the problems which are now solved and the data still under controversy.

The sperinatogenetic process is 8 days long. It is 24 hours longer in the immmature testis. Similarly I,000 r X-radiations 48 hours after emergence induce a 24 hours delay. The sperinatogenesis is thought to proceed at constant rate; however, some authors think that sperm demand has no influence ons perm formation, others think that the two rates are interrelated. 'Therefore, the importance of sperm resorption and storage in the male is not well known.

The average number of spermatozoa inseminated at first mating is 4,000. The male's fertility, estimated with regard to the offspring, reaches a maximum $7^{2}$ hours after the imago has become fully mature. Then, it regularly decreases until the 3 oth day and results in a senile period the cause of which is unknown. A male's progeny is found to be 3,980 flies or 10,000 to 14,000 according to the authors. This number depends on the sire's strain and life span.

A 3 days old male can fertilize about ro females within 24 hours. Sequential matings within 2 to 4 hours induce a natural sterility which originates in the exhaustion of accessory gland secretion. This paragonial secretion is essential to spern transfer both in male and female ducts.

Matings occur more or less quickly in relation with the genotypes of the strains mated.

Males's fertility is much lower if they are 4,000 $\mathrm{r}$ at least $\mathrm{X}$-irradiated before mating. $\mathrm{X}$-rays seem to influence spermatozoan motility.

Temperatures higher than $30^{\circ} \mathrm{C}$ or lower than $4^{\circ} \mathrm{C}$ induce male sterility, provided that the animals be subjected to it fore one week or more.

In the female, only is to $20 \mathrm{p}$. 100 (500 to 700 ) of the spermatozoa initially inseminated are stored in the ventral receptacle and spermathecae. Therefore, a great amount of sperm must be wasted during the storage process.

Strain differences influence sperm migration in the female storage organs which fill more or less with sperm according to the inter-and-intra-strain crosses effected. This variation is expressed by the "insemination index " so called by Yanders.

The process of sperm utilization by the female is not clear. It has been suggested that the venrtral receptacle remains open and that the spermatozoa keep on moving inside it. On the contrary Garcia BELLIDo is led to suggest that the ventral receptacle would remain closed and the paragonial secretion be responsible for its opening.

The idea of monospermy has now trickled out from a formerly wide-spread belief in polyspermy. As for double-mating experiments, the most reliable hypothesis may be that of the displacement of the first sperms by the second one.

Annales de Biologic animale. - Ig66. 
The number of spermatozoa stored in the female can be reduced through different factors : senility, inadequate feeding, chill : chilled $\left(0^{\circ} \mathrm{C}\right)$ female's fertility is significantly lower. It has been suggested that the sexual receptivity of virgin females is inhibited after the first mating, first at the neural level, second by means of a chemical agent contained in the sperm but this is hypothetic.

Fertilization leads to differences in the laying and size of the egg. The stimulus for the maintenance of fecundity is thought to be either the state of repletion of the ventral receptacle or a chemical agent in the paragonial secretion.

\title{
RÉFÉRENCES BIBLIOGRAPHIQUES
}

\author{
Abréviations utilisées : D : Drosophila ; D. m.: Drosophila melanogaster ; \\ D.I.S.: Drosophila Information Service
}

Aвоїм A. N., I945. Développement embryonnaire et post-embryonnaire des gonades normales et aganiétiques de D. m. Rev. Suisse Zool., 52, 53-I 54 .

ÅвRо A., т965a. On the synchronous différentiation of spermatogenic cells in D.m. Meigen. Ab. Univ. Bergen, mal - naturvitensk.. Ser. no 1-19.

Åвro A., 1965. b. Cytological observations on spermiogenesis in $D . m$, Meigen. A $b$. Univ. Bergen, mat. - naturvitensk., Ser. $n^{\circ}$ 1-19. I-23.

Auerbaci $\mathrm{C}$., 1954. Sensitivity of the D. testis to the mutagenic action of X-rays. Z. indukt. Abslamm.. u. Vererb Lehre, 86, I $13-125$.

BAKER R. M., t96o. The effect of cold temperature on fertility. D.I.S., 34, 7o.

Baker, W. K. VON HALLE E. S., I953. The basis of the oxygen effect on X-irradiated D. sperm. Proc. Nat. Acad. Sci. Wash., 39, i 52-16r.

Bastock M., Manning A., I955. The courtship of Drosophila melanogaster. Proc. Roy. Soc. Ser. B., 133. I-I 9 .

BIsilop G. II., 1920. J. Exp. Zool., 31, 225-266.

Blum M. S., Glowska Z., Taber S., r962. Chemistry of the drone honey bee reproductive system. II. Carbohydrates in the reproductive organs and semen. Ann. Entomol. Soc. Amer., 55, I $35^{-1} 39$.

Bodenstein D., I950. The postembryonic development of Drosophila, in : DemereC M. Biology of D., chap. IV, 275-367. Wiley, New York.

Bösiger E., i960. Sur le rôle de la sélection sexuelle dans l'évolution. Experientia, 16, 270-273.

Bösıger E., I962. Degré d'hétérozygotie des populations naturelles de $D . m$. et son maintien par la sélection sexuelle. Bull. Biol. Fr. Belg., 96, 3-122.

Bösiger F., ig63. Comparaison du nombre de descendants engendrés par des mâles homozygotes et des mâles hétérogzyotes de D.m. C.R. Acad. Sci. Fr., 257, 531-533.

Carayon J., I964. Spermathèque et voies génitales femelles des Lygaeideat axycareninte (Heteroptera). Revue fr. Entom., 31, 196-2 18.

Chandeey A. C., Bateman A. J., 1962. Timing of spermatogenesis in $D$. $m$. using tritiated thymidine. Nature, 193, 299-300.

Chauvin F., 1956. Physiologie de I'Insecte, $2^{\mathbf{e}}$ Édition, I.N.R.A., Paris, 916 p.

Chen P. S., DIEm C., I96r. A sex-specific ninhydrin-positive substance found in the paragonia of adult males of D. m. J. Insect. Physiol., 7, $289-298$.

CoOper K. W., 1950. Normal spermatogenesis in D., in : Demerec M. Biology of Drosophila, chap. I, I-16. Wiley, New York.

Counce S. J., 1956. Studies on female sterility genes in $D . m$. The effects of the gene deep orange on embryonic development. Z. indukt. Abstamm.- u. VererbungsLehre, 87, 443-46r.

Counce S. J., I959. Spermatozoa in D. eggs. D.I.S., 33, 127-128.

Counce S. J., I963. Polyspermy in D. : a reexamination. D.I.S., 37, 69 .

Daems W. Th., Persijn J. P., Tates A. D., I963. Fine structural localization of ATPase activity in mature sperm of D. m. Exp. Cell. Res., 32, 163-I67.

Davey K. G., I958. The migration of spermatozoa in the female of Rhodnius prolixus STÄL. J.exp. Biol. 35, 694-70I.

DaveY K. G., 1965. Reproduction in the Insects, I28 p. ; University Review in Biology. Oliver and Boyd : Edinburgh, $96 \mathrm{p}$.

David J., 1963. Influence de la fécondation de la femelle sur le nombre et la taille des œufs pondus. Étude chez D. m. MEIG. J. Ins. Physiol., 9. I $3^{-24}$. 
David J., I965. Communication personnelle.

David J., Crorssant J., 1956. Recherches sur la fécondité et la fertilité chez D. m. veig. Ann. Univ.

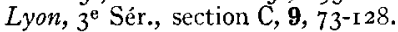

DeL Solar E., I964. Effects of crowding on sexual activity in D.m. D.I.S., 39, II4-II5.

Demerec M., 1950. Biology of Drosophila. John Wiley and Sons, Inc., New York, $63^{2}$ p. et (1965) Hafner publishing Company N. Y. and London. (réimpression).

Demerec M., KaUfmans B. P., i94r. Time required for $D$. males to exhaust the supply of mature sperm. Amer. Nat., 75, 366-379.

DE VRIEs J. K., 1964. Insemination and sperm storage in D. m. Evolution. U.S.A., 18, 27 I-282.

De Wilde J., I964. Reproduction, vol. I, chap. II et III, p. 9-90, in Rockstein II. The Physiology of Insecls. Academic Press, N. Y.-London.

DOANE W., Ig6r. Developmental physiology of the mutant female sterile (2) Adipose of D. $m$. III. Corpus allatiun-complex and ovarian transplantation. J.exp. Zool., 146, 275-298.

Dubinis N. P., ig28. Influence of repeated fertilization upon the character of the offspring in D.m. J.exp. Biol., 4, I $3^{\mathrm{I}-\mathrm{I}} 59$. (en russe)

Duncan F. N., i93o. Some observations on the biology of the male D. m. Amer. Nat., 64, 545-551.

EhrLICI E. F., r959. The pattern of sperm utilization by multiply inseminated fenales. D.I.S., 33, I29-I 30 .

Fox A. S., 1956, $a$. Chromatographic differences between males and females in $D . m$. and role of $\mathrm{X}$ and $\mathrm{Y}$ chromosomes. Physiol. Zoöl., 29, 288-298.

Fox A. S., 1956, b. Paper chromatographic studies of the effects of the lozenge pseudo alleles on free amino acids and peptides in D. $\mathrm{m}$. Z. indukt. Abstamm.-u. Vererb Lehre, 87, 554-566.

Frydenberg 0. Sick K., ig6o. Desemination by cold shocks. D.I.S., 34, 79 .

Garcia-Bellido A., I 964. Das Sekret der Paragonien als Stimulus der Fekundität bei Weibchen von $D . m$. Z. Naturforsch, $B$, Disch., 19, $49 \mathrm{I}-495$.

Glass H. B., Plaine H. L., 1950. 'The immediate dependance of the action of a specific grene in $D . m$. upon fertilization. Proc. Nat. Acad. Sci. Wash., 36, 627-634.

Gotrsciewski G., 1937. Künstliche Befrüchtung bei Drosophila. Nalurvissenschatien, 25, 650.

Groscr D. S., I962. Entomological aspects of radiation as related to genetics and physiology. Ann. Revieve Entomol., \%, 8I-106.

GiJgLer H. D., KAPLAN W. D., KIDI K., I 965 . The displacement of first mating by second-mating sperm in the storage organs of the female. D.I.S., $\mathbf{4 0 , 6 5 .}$

Guyénot E., rgı. Études biologiques sur une mouche, Drosophila ampelophila Löw. '. Résorption des spermatozoïdes et avortement des œufs. C. R. Soc. Biol. Paris, 74, 389-39I.

Guyénot E., Naville A., ig29. Les chromosomes et la réduction chromatique chez D. m. (Cinèses sonatiques, spermatogenèse, ovogenèse). La Cellule, 39, $25-82$.

HADORN E., I958. Role of genes in developmental processes. In : The chemical basis of development, p. 779793. Baitimore, The Johns Hopkins Press.

Hadorn E., Bertani G., Gallera J., I949. Regulationsfähigkeit und Feldorganisation der männlichen Genital-Imaginalscheibs von D.m. Roux' Arch. Entro. Mech. Org., 144, 31-7o.

HADORN E., ZELLER M., I943. Fertilitätstudien an D. $m$. I. Untersuchungen zum altershedingten Fertilitätsabfall. Roux'Arch., 142, $276-300$.

Hannah-Alava A., Puro J., i964. The brood pattern of fecundity of $D . m$. males mated singly and sequentially up to 24 days. D.I.S., 39, 1 22-1 24 .

Hanson F. B., Heys F., i929. Duration of the effects of X-rays on male germ cells in D. m. Amer. Nat., 63, 5 I $1-5$ I 6.

HARRIS B. B., I929. The effects of aging of X-rayed males upon mulation frequency in Drosophila. J. Hered, 20, 299-302.

Herskowitz I. M., I952. Bibliography on the Genetics of Drosophila. Part tioo. Commonwealth Agricultural Bureaux Farnham Royal, Slough, Bucks.

Herskowitz I. N., I958. Bibliography on the Genetics of Drosophila. Part three. Bloomington, Indiana University Press.

Herskowitz I. M., I963. Bibliography on the Genetics of Drosophila. Part four. Ne Graw-Hill Book Company, Inc. New York.

Hildretil P. E., LucchesI J. C., I96I. Fertilization in D. m. and D. virilis. D.I.S., 35, 85 .

Hildreth P. E., LuCChesi J. C., I962. Low incidence of polyspermy in D. m. and D. virilis. Genetics, 47, $95^{8-959 .}$

Hildreth P. E., Lucchesi J. C., I963, a. Frequency of dispermy in D. m. D.I.S., 37, s9.

Hildreti P. E., Lucchesi J. C., I963, b. Fertilization in $D$. (I). Fvidence for the regular occurence of monospermy. Develop. Biol., 6, 262-278.

Hoenigsberg H. F., i96o. Sexual behavior : a discussion. Evolution, 14, 527-528.

Hoenigsberg H. F., Santibanez S. K., 1960. Courtship and sensory preferences in inbred lines of. $D$. $m$ Evolution, 14, I-7. 
Ilowie D. I. D., McClenaginai C. M., I965. Evidence for a feed back mechanism influencing spermatogonial division in the Lugworm (Arenicola marina L.). Gen. Comp. Endocrinol., 5, 40-44.

Iluetrner A. F., 1924. Maturation and fertilization in D.m. J.morph. Physiol., 39, 249-265.

Huetrener A. I., 1927. Irregularitics in the early development of the D. $m$. egg. Z. Zellforsch. u. mikr. Anat., 4, 599-610.

Huertner A. F., r93o. The spermatogrenesis in D. m. Z. Zellforsch. u. mikr. Anal., 11, 61 5-637.

IYENGAR S. V., BAKER R. M., rg62. The influence of temperature on the pattem of insemination by $D . m$. males. Genelics, 47, 963-964.

KAPLAN W. D., SiskEN J. E., I960. Genetic and autoradiographic studies of tritiated thymidine in testes of D.m. Experienia, 16, 67-69.

Kaplan W. D., TinderiolT V. E., Gugler D. H., i 962. The number of sperm present in the reproductive tracts of D. m. females. D.I.S., $\mathbf{3 6}, 82$.

Kaufmann B. P., Demerec M., i942. Utilization of sperm by the female D. m. Amer. Nal., 76, 445-469.

Kerr W. E., Zucchi R., Nakadaira J. I., Butolo J. F., 1962. Reproduction in the social Bees (Hymenoptera : Apidae). J. V. Y. Entonol. Soc., 70, 265-276.

Keuchenius P. E., r913. The structure of the internal genitalia of some male Diptera Z. Wiss. Zool., $105,50 \div-536$.

KuIsinn A. F., 1955. The response of the immature test is of $D$. to the mutagenic action of X-rays. Z.induktAbstamm, i. VererbLehre, 8\%, 97-I 12.

Kirisinin A. F., I957. On the development of male germ cells in D. $m$. Cytologia, 22, 28-29.

Kunner H., ig60. Lixperimentelle Untersuchungen zur Wirkung von Fortpflanzungs-Faktoren auf die Lebensdaucr von $D . m$. Z. vergl. Physiol., 43, 642-679.

KVELLAND I., Ig65, a. Somes observations on the mating activity and fertility of $D$. m. males. Ilereditas, 53, 28I-306.

Kvelland I., 1965, b. Mating and fertility Pattern of $D$. $m$. males exposed to different temperatures. Hereditas, 54, 88-100.

LEAliy M. G., I966. Egg deposition in D. m. increased by transplant of male paragonia. D.I.S., 41, I45-146.

Lefevre G. Jr., Jonsson U. B., 1962, a. Sperm relationships in twice-mated D. m. females. D.I.S., 36, $85-86$.

Leffyre G. Jr, Jonsson U.B., ig62, b. The effect of cold shock on D. m. sperm. D.I.S., 36, 86-87.

Jefevre G. Jr, Jonsson U. B., J962, c. Sperm transfer, storage, displacement, and utilization in $D . m$. Genetics, 47 , I 7 I $9^{-1} 73^{6}$.

Lefevre G. Jr, Jonsson U. B., T964. Mutability of mature sperm following irradiation of virgin males and inseminaterl females. D.I.S., 39, 120-122.

Lefevre G. Jr, Parker D. M., 1963. Male fertility as a function of the number of females available for mating. D.I.S., 37, 98.

Lobasirov M. F., 1939. Mixture of sperm in case of polyandry in D.m. C.R. Acal.Sci. L.R.S.S.,23, $827-830$.

LiNING K. G., 1952. X-ray induced dominant lethals in different stages of spermatogenesis in 2 . Ioreditas, 38, 91-I07.

Liining K. G., 195+. Effects of oxygen on irradiated males and females of Drosophila. Heredilas, 40, $295-3$ I 2.

MAC BeAN I. T., PARsons P. A., Ig66. The genotypic control of the duration of copulation in $D . m$. Experientia, 22, 1ог-102.

Mande A. M., I954. The radiosensitivity of germ cells. Biol. Rev., 39, 288-37 .

Mavning A., I96r. The effect of artificial selection for mating speed in D. m. Anim. Behaziour, 9, 82-92.

Manving A., $1952, a$. A sperm factor affecting the receptivity of $D$. m. females. Nalure, 194, $25^{2-253}$.

Mavnivg A., $1962, b$. The control of sexual receptivity in female Drosoplita. Anim. Behaviour, $10,384$.

Martin A. O., 1965. Studies on the rate of spermatogenesis in Drosophila. Effects of X-rays and streptonigrin. Z. Vererbungsl., 96, 28-35.

McSireehy T. W., I963. Mating frequency in D. m. D.I.S., 37, го .

Meyer H. U., 1956. Failure of inseminated females to produce fertilized eggs unless additional copulation takes place. D.I.S., 30, I 35 .

Meyer H. U., Meyer E. R., i 96 . Sperm utilization from successive copulations in females of $D . m$. I).I.S., 35, 90-92.

Mossige J. C., r955. Sperm utilization and brood patterns in D. m. Amer. Nat., 89, i23-r27.

Mouciet J., RAGEAU J., i963. La stérilisation sexuclle ct l'autodestruction de l'espèce dans la lutte contre lus Insectes. Maroc Médical, 45\%, 42-63.

Muller H. J., 1939. Bibliography on the Genetics of Drosophila. Edinburgh, Oliver and Boyd.

Muller H. J., I940. An analysis of the process of structural change in chromosomes of $D$. J. Genetics, 40, $\mathrm{I}-66$.

Muller II. J., Settles F., r927. The non-functioning of the genes in spermatozoa. Z. indukt. Abslamm.1i. VererbLehre, $43,285^{-3}$ I 2 . 
Myszewski M. E., Yanders A. F., I963. The effect of storage upon the differential survival among sperm. D.I.S., 38, $35^{-} 3^{6}$.

Nacirsileim H., 1927. Jine Methode zur Prüfung der Lebensdauer genotypisch verschiedener Spernien bei Drosophila. Verh. V. Int. Kongr. Vererbungsiv, I1+3-1147.. Z. Indukt. Abstamm.- u. VererbLehre, Suppl. II (1928).

Nonidez J. F., 19zo. The internal phenomena of reproduction in Drosophila. Biol. Bull., 39, 207-23o.

Novitsis E., Rush G., I948. Desemination by low-temperature shocks. D.I.S., 22, 75 .

Oster I. I., 196r. On recovery in X-irradiated germ cells. J. cell. comp. Physiol., Suppl. I, 58, $203^{-207 .}$

Parsons P. A., I964. Genotypic control of mating times in 1 . m. Experientia, 20, 569-570.

Parsons I.A., 1965. The determination of mating speed in $D$. $1 n$. for various combinations of inbred lines. Experientia, 21, 478 .

PAYNe II. A., 1933. J. Morph., 54, $321-346$.

Petrt C., I958. Le déterminisme génétique et psycho-physiologique de la compétition sexuelle chez $D . m$. Bull. Biol. Fir. Belg., 92, 248-329.

Philip U., ig42. Meiosis in Drosophila. Nature, 149, 527-528.

Rockstern A., I964. The Physiology of Insecta, 1, Academic Press. New York.

Scossiroli R. E., 1954. Dz-semination of fertilized D. m. females. Phy'siol. Zoöl., 27, I 57-162.

Shapiro N. I., I93I. The influence of the age of grem-cells on the origination of translocation in $D . m$. (en russe). Zh. Exp. Biol., 7, 370-348.

Sigot A., I953. Contribution à l'étude de la sensibilité héréditaire au gaz carbonique chez la Drosophile. Influence de divers facteurs sur la transmission de la sensibilité par les máles. Bull. Biol. Fr. Belg., 87, $335-413$.

Smith J. М., t956. J. Genet., 54, 26r.

Sonnenblick B. P., I950. The early embryology of D.m., in Denerec M. Biology of Drosophila, chap. II, 62-I67. Wiley, New York.

Spiess F. B., LANGer B., ig5ł. Mating speed control by genes arrangements in Drosophila pseudo-obscura ho:nokaryotypes. Proc. Nat. Acad. Sci. U.S.A., 51, Ior5-Ioro.

Strijnvae; O., Kvelland I., I962. Sexual activity of $I$ ). m. males. Hereditas, 48, 442-4jo.

Trues J.A., 1946. An estimate of the number of cell generations preceding sperm formation in $D . m$. Amer. Nal., 80, $389-393$.

Timoféefi-Ressovsky N. W, i93o. On gene-action in germ cells. Zh. Exp. Biol., 6, i81-187 (en russe).

Timoféelic-Ressovsky N. W., 193r. Einige versuche an $D$. $m$. über die Art der Wirkung der Röntgenstrahlon auf den Mutations prozess. Roux'.1rch. Ento. Mech. Org., 124, 654-665.

Traut II., ig66. Radiation-induced mitotic delay in spermatogenesis of D. $\mathrm{m}$. Nature, 209, 92-93.

Trosko J. E., Yanders A. F., i963. Cold storage effect on irradiated Drosophila sperm. D.I.S., 38, 36-37.

Von Borjtel R. C., Lindjley D. L., I959. Insect embryo chromosome technique. Stain Technol., 34, $23-26$.

Wedvik M., ig62. The effect of low temperature on fertility of D. m. males. D. I.S., 36, 127.

Weidner H, 1934. Beitrage zur Morphologie und Physiologie des genital apparates der weiblichen Jepidopteren. Z. angew. Entoinol., 21, 239-29o.

WheELER II. R., 1947. The insemination reaction in intraspecific matings of Drosophila. Univ. Texas Publ., 4720, 78-i I5.

Wigglesworti V. B., I965. The Principles of Insed Phy'siology. Sixth Ed., 74I p. Methuen, London.

YANDER; A. F., 1963 . The rate of D. m. sperm migration in inter-and intra-strain matings. D.I.S., 38, 33 .

YANDER; A. F., 1964. The effects of X-rays on insemination and sperm retention in Drosophila. Genetics, 49, 309-317.

Yanders A. F., Perras J. F., r960. Sperm lenght in four Drosophila species. D.I.S., 34, I 2.

Young W. C., Plougil H. H., 1926. On the sterilization of Drosophila by high temperature. Biol. Bull., 51, I $89-198$. 